\title{
Operation-based flowtime estimation in a dynamic job shop ${ }^{\text {th }}$
}

\author{
I. Sabuncuoglu*, A. Comlekci \\ Department of Industrial Engineering, Faculty of Engineering, Bilkent University, Ankara 06533, Turkey
}

Received 21 August 2000; accepted 5 September 2002

\begin{abstract}
In the scheduling literature, estimation of job flowtimes has been an important issue since the late 1960s. The previous studies focus on the problem in the context of due date assignment and develop methods using aggregate information in the estimation process. In this study, we propose a new flowtime estimation method that utilizes the detailed job, shop and route information for operations of jobs as well as the machine imbalance information. This type of information is now available in computer-integrated manufacturing systems. The performance of the proposed method is measured by computer simulation under various experimental conditions. It is compared with the existing flowtime estimation methods for a wide variety of performance measures. The results indicate that the proposed method outperforms all the other flowtime estimation methods. Moreover, it is quite robust to changing shop conditions (i.e., machine breakdowns, arrival rate and processing time variations, etc.). A comprehensive bibliography is also provided in the paper.
\end{abstract}

(C) 2002 Elsevier Science Ltd. All rights reserved.

Keywords: Flowtime estimation; Due date assignment; Simulation; Scheduling

\section{Introduction}

In the job shop scheduling literature, estimation of job flowtimes has always been an important issue since the late 1960s. Because the flowtime estimation is used to assign order due dates, the problem has been mostly studied within the context of due date assignment. In several previous studies $[1,2]$, the term due date assignment has been often used to describe the problem. However, beyond the objective of due date setting, accurate flowtime estimates are also needed for better management of the shop floor control activities, such as order review/release, evaluation of the shop performance, identification of jobs that requires expediting, leadtime comparisons, etc. All these application areas make the problem as important as other shop floor control activities (i.e., scheduling).

\footnotetext{
Th This research is partially supported by Scientific and Technical Research Council of Turkey (TUBITAK).

* Corresponding author. Tel.: +90-312-266-4477; fax: +90-312266-4126.

E-mail address: sabun@bilkent.edu.tr (I. Sabuncuoglu).
}

The research problem studied in this paper is the estimation of the jobs' time spent in the system from their arrival until the completion of all processing activities. The difficulty of the problem stems from the dynamic and stochastic nature of the job shop environments (i.e., arrival of hot jobs, sudden machine breakdowns and variations in machining conditions, etc.) that precludes accurate predictions.

The existing studies in the literature examine the problem by identifying the key information sources required in flowtime estimation. The results indicate that job- and shop-related information are the key elements in the estimation process. Researchers (e.g. [3]) used these information sources in aggregate terms by ignoring the benefits of using more detailed shop and route congestion information in the flowtime estimation. Other important findings which motivated our study to develop a new flowtime estimation method are as follows.

First, previous studies indicate that total load on the route of an arriving job provides valuable information in flowtime estimation [3-7]. We also expect that the distribution of the work load on the machines is as important as the total load itself. The load information of the machines nearer 
to the beginning of the route of the job would affect the flowtime of that job more than the load of the machine closer to the end of its route, because the system state can be considerably different when the job arrives at these machines for its later operations. Thus, splitting the route information in terms of operations of the job can improve the quality of the flowtime estimation. Second, previous research also indicate that consideration of total load of the jobs elsewhere in the shop (i.e. the jobs which are not currently at the machines on the route of the arriving job, but will visit them later for processing) is also important [8]. This is because these jobs will eventually bring additional workloads to the route of the arriving job. Hence, both timing and distribution of these so called "other jobs" should also be taken into account in the estimation process.

Third, as shown by several researchers, dispatching rules affect the performance of the flowtime estimation methods [3,9-14]. For example, Ragatz and Mabert [3] use different flowtime estimation models for different dispatching rules. Finally, it is observed that the performance of the flowtime estimation methods are significantly affected by the load balance in the shop (e.g., [5]).

In this study, we develop a new method by using these four observations outlined above. Specifically, the proposed method estimates flowtimes by employing the detailed job, shop and route information for each operation of a job as well as considering the machine imbalance and dispatching rule information. Results indicate that it is quite effective in using these information sources to achieve better system performance.

The rest of this paper is organized as follows. In Section 2, we present a literature survey. In Section 3, basic structure and characteristics of the proposed method are described. The key components of the model are also discussed using an illustrative example. In Section 4, we define the experimental design and give the details of the simulation model. Computational requirements of the proposed study are discussed in Section 5. Results of the simulation experiments and statistical tests are presented in Section 6. Finally, the concluding remarks are made and further research directions are outlined in Section 7.

\section{Review of the literature}

Due date assignment is one of the main application areas of flowtime estimation. As it is frequently observed in the literature, most research efforts directed towards flowtime estimation are within the context of due date assignment $[4,12,15]$. Hence, we will also review the due date assignment literature to the extent that it deals with flowtime estimation in production systems.

There are basically two flowtime estimation approaches in the literature: analytical approach and simulation approach. Cheng and Gupta [10] present an extensive survey of both of these approaches for the due date assignment problem.
They also provide a framework for the scheduling problems in the due date assignment process. There are advantages and disadvantages associated with each approach. The analytical approach offers an exact way of determining mean and variances of flow time estimates. However, the dynamic and stochastic nature of production systems makes it difficult to develop realistic analytical models. On the other hand, simulation approach does not always produce reliable estimates. Moreover, a great number of computer runs may also be needed in the latter case to obtain the accurate and precise estimates. Since these two areas are complimentary in nature, the literature has been developed in both directions. Our primary focus in this paper is on the simulation methodology. Thus, we next discuss the simulation related research in detail. For the analytical studies, the reader can refer to the following research papers: Miyazaki [14], Enns $[13,16,17]$ Cheng [18,19], Shanthikumar and Buzacott [20], Buzacott and Shanthikumar [21], Shanthikumar and Sumita [22], and Lawrence [23]. The recent trend in analytical studies is to determine flowtime prediction errors and distribution functions so that leadtime estimates can be derived (Enns [24] and Lawrence [23]).

The first simulation-based study in this area is conducted by Conway [11] who compares four flowtime estimation methods: total work content (TWK), number of operations (NOP), constant (CON), random (RDM). The results of this study indicate that the methods which utilize the job information perform better than the others. Conway also observes the relationship between due date assignment methods and dispatching rules. Later, Eilon and Chowdhury [4] use shop congestion information in estimating flowtimes. In this work, TWK is compared with three other methods: jobs in queue (JIQ), delay in queue (DIQ) and modified total work content (MTWK). Results indicate that JIQ, which employs the shop congestion information, outperforms other methods.

In another study, Weeks [25] proposes a method which combines both the job and shop information. This method performs very well for the performance metrics such as mean lateness, mean earliness, and number of tardy jobs. The results also indicate that flowtime estimation is affected by the structural complexity of the shop more than the size of the system. Later, Bertrand [5] proposes a new method of flowtime estimation which exploits time-phased workload information of the shop. Two factors are used in analyzing the performance of the method: minimum allowance for waiting (SL) and capacity loading limit (CLL). His results indicate that time-phased workload and capacity information significantly decrease variance of the lateness.

Ragatz and Mabert [3] compare eight different methods: TWK, NOP, TWK-NOP, JIQ, WIQ (similar to JIQ except that the total processing times of jobs on the route is used instead of the number of them), WEEK's method, JIS (similar to JIQ except that the number of jobs at the system is used instead of the number of jobs on the route), and response mapping rule (RMR). Among them, RMR utilizes 
thek response surface methodology to identify the significant factors in flowtime estimation. The results indicate that the job and workload information along the process routes are very important for predicting flowtimes.

In another study, Cheng [9] exploits a hypothetical job shop to determine the main and interaction effects of due date assignment methods, dispatching rules, and shop load ratios. Multiple regression analysis is used to identify relations between these factors for the percentage of late jobs measure. Kanet and Christy [26] compare TWK with the processing plus waiting (PPW) method via computer simulation in a job shop with forbidden early shipment. PPW estimates a job's flow allowance by adding an estimate of the waiting time, which is proportional with the number of operations, to the total processing time of a job. The results indicate that TWK is superior to PPW in terms of the mean tardiness, proportion of tardy jobs, and mean inventory level measures. Fry et al. [27] also investigate the job and shop characteristics which affect a job's flowtime in a multistage job shop. They construct two linear and two multiplicative nonlinear models to estimate the coefficients of the factors. This study shows that (1) models using product structure and shop conditions estimate flowtimes better than the others, (2) linear models are superior to the multiplicative models, and (3) the predictive ability of the models also improves as the utilization increases.

Vig and Dooley [6] propose two new flowtime estimation methods: operation flowtime sampling (OFS) and congestion and operation flowtime sampling (COFS). These methods are also compared with JIQ and TWK-NOP under various shop conditions. The results indicate that COFS and JIQ yields the overall best performance. Vig and Dooley [7] extend their work by combining static and dynamic estimates to obtain job flowtime estimates. In this method, the dynamic estimates are produced obtained by COFS and OFS.

Gee and Smith [8] propose an iterative procedure for estimating flowtimes when due date dependent dispatching rules are used. Two flowtime estimation methods are employed, the one is based on local (job related) information and the other one utilizes global (both job and shop related) information. Their results indicate that the global rule yields better estimation. They also compare the iterative approach with the RMR approach of Ragatz and Mabert [3] and find that the quality of flowtime estimation is improved by the iterative approach when used with due-date based dispatching rules. Later, Enns $[16,17]$ proposes a dynamic estimation method which employs a dynamic version of the PPW method. By using exponentially smoothed flowtime estimation error feedback, the lateness variance is estimated. The author also describes a method of setting due dates to achieve of the desired percentage of tardy jobs. In a recent study, Enns [24] develops a new work load balancing dispatch mechanism and investigates the relationships between internal and external measures. The results indicated that a new shop load balance index which considers both shop load and variability has a very strong relations with lead times.

In another study, Kaplan and Unal [28] propose a cost based model in setting due dates. In this approach, the due dates are calculated by summing the flowtime estimate with a multiple of the estimated standard deviation of the flowtime estimation error. Their procedure is composed of two stages. In the first stage, a flowtime estimation model is derived. In the second stage, the coefficient are obtained by optimizing the total cost function.

Finally, Philipoom et al. [29] investigate the feasibility of using neural networks in flowtime estimation. In this study, the authors estimate the coefficients of the methods with neural networks instead of multiple regression. The results indicate that the neural network approach offers certain advantages over the conventional approaches. From the above literature review, we make the following observations:

- There are significant interactions between the flowtime estimation methods and the dispatching rules. Hence, the dispatching rule used in a system influences the performance of the flowtime estimation method [9-14,3].

- Both shop and job characteristics are important for flowtime estimations [3,5-7,11,13,14,3,6,7,25,30].

- Splitting the shop congestion information as the load on the route and the load out of the route enhances predictive power of the flowtime estimation methods. Especially, the load information along the route of a job is seen to be more useful than the other general shop information $[3,4,6,7]$.

- Due date based dispatching rules perform better than the due date independent rules $[4,17]$.

- Shop balance information significantly affects the performance of the flowtime estimation methods $[6,7,28]$.

- Using aggregate information leads to almost the same performance when compared with the use of more detailed information with RMR [3].

\section{Proposed method}

In this section, we describe the basic structure and characteristics of the proposed flowtime estimation method. First, we outline the main ideas that motivated us to develop a new model.

(1) Previous studies indicate that total load on the route of an arriving job provides valuable information in flow time estimation [3-7]. We also expect that the distribution of the work load on the machines is as important as the total load itself. The load information of the machines nearer to the beginning of the route of the job would affect the flowtime of that job more than the load of the machine closer to the end of its route, because the system state can be considerably different when the job arrives at these machines for its later 
operations. Thus, splitting the route information in terms of operations of the job can improve the quality of the flowtime estimation.

(2) Previous research also indicate that consideration of total load of the jobs elsewhere in the shop (i.e. the jobs which are not currently at the machines on the route of the arriving job, but will visit them later for processing) is also important [8]. This is because these jobs will eventually bring additional workloads to the route of the arriving job. Hence, both timing and distribution of these so called "other jobs" should also be taken into account in the estimation process.

(3) Many researchers have demonstrated that dispatching rules affect the performance of the flowtime estimation methods [3,9-14]. For example, Ragatz and Mabert [3] use different flowtime estimation models for different dispatching rules. In this study, we also employ different dispatching rules. But the use of dispatching rule information is quite different in our case; instead of using a separate flowtime estimation model for each rule, we use the same model but measure the values of the variables in a different way for each dispatching rule. For example, when total work load is used as a variable in the model, the total operation times of all the jobs in the queue is calculated for the FCFS rule whereas the total operation time of the jobs with smaller operation times than the arriving job is used for the SPT rule. Thus, the measurement of the variables in our model is slightly different for each dispatching rule.

(4) Previous studies indicate that the performance of the flowtime estimation methods are significantly affected by the load balance in the shop. Bertrand [5] uses this information implicitly in the model. In our study, however, we will explicitly consider the long run shop load balance information.

\subsection{Model}

We now give the detail structure of the proposed model whose motivating points are discussed in the introduction section. The following variables are used:

(a) Total work load on the machine at which the job is to be processed.

(b) Total load of the jobs elsewhere in the shop (i.e., at other machines), but are expected to visit that machine during the time the job under consideration is processed.

(c) Processing time of the job.

The generic regression model is as follows:

$\mathrm{PF}_{j i}^{k}=c_{1 j}^{k} X_{1 j i}^{k}+c_{2 j}^{k} X_{2 j i}^{k}+c_{3 j}^{k} X_{3 j i}^{k}$,

where $\mathrm{PF}_{j i}^{k}$ is the partial flowtime of job $i$ for its $k$ th operation at machine $j . X_{1 j i}^{k}$ is the sum of processing times of the relevant jobs ${ }^{1}$ at the queue of machine $j$ that job $i$ will have its $k$ th operation. $X_{2 j i}^{k}$ is the sum of processing times (on machine $j$ that job $i$ will have its $k$ th operation) of the relevant jobs at the machine queues other than machine $j$ but require machine $j$ in the future. $X_{3 j i}^{k}$ is the processing time of job $i$ at machine $j$ for its $k$ th operation. $c_{1 j}^{k}, c_{2 j}^{k}, c_{3 j}^{k}$ are the regression coefficients.

When job $i$ arrives to the system, the $\mathrm{PF}_{j i}^{k}$ values are calculated for each operation by using the above equations. Then, the total flowtime estimate $F_{i}$ is the summation of these values.

In the balanced shop case (i.e., the case in which the long term utilization of the machines are nearly the same), the above model is simplified by removing the machine index from the formulation. Hence, we have

$\mathrm{PF}_{i}^{k}=c_{1}^{k} X_{1 i}^{k}+c_{2}^{k} X_{2 i}^{k}+c_{3}^{k} X_{3 i}^{k}$

The meaning of the variables are the same as before. For example, the following equations need to be developed for an unbalanced job shop with 5 machines

Machine 1:

$$
\begin{aligned}
& \mathrm{PF}_{1 i}^{1}=c_{11}^{1} X_{11 i}^{1}+c_{21}^{1} X_{21 i}^{1}+c_{31}^{1} X_{31 i}^{1} \\
& \mathrm{PF}_{1 i}^{2}=c_{11}^{2} X_{11 i}^{2}+c_{21}^{2} X_{21 i}^{2}+c_{31}^{2} X_{31 i}^{2} \\
& \mathrm{PF}_{1 i}^{3}=c_{11}^{3} X_{11 i}^{3}+c_{21}^{3} X_{21 i}^{3}+c_{31}^{3} X_{31 i}^{3} \\
& \mathrm{PF}_{1 i}^{4}=c_{11}^{4} X_{11 i}^{4}+c_{21}^{4} X_{21 i}^{4}+c_{31}^{4} X_{31 i}^{4} \\
& \mathrm{PF}_{1 i}^{5}=c_{11}^{5} X_{11 i}^{5}+c_{21}^{5} X_{21 i}^{5}+c_{31}^{5} X_{31 i}^{5}
\end{aligned}
$$

Machine 2:

$$
\begin{aligned}
& \mathrm{PF}_{2 i}^{1}=c_{12}^{1} X_{12 i}^{1}+c_{22}^{1} X_{22 i}^{1}+c_{32}^{1} X_{32 i}^{1} \\
& \mathrm{PF}_{2 i}^{2}=c_{12}^{2} X_{12 i}^{2}+c_{22}^{2} X_{22 i}^{2}+c_{32}^{2} X_{32 i}^{2} \\
& \mathrm{PF}_{2 i}^{3}=c_{12}^{3} X_{12 i}^{3}+c_{22}^{3} X_{22 i}^{3}+c_{32}^{3} X_{32 i}^{3} \\
& \mathrm{PF}_{2 i}^{4}=c_{12}^{4} X_{12 i}^{4}+c_{22}^{4} X_{22 i}^{4}+c_{32}^{4} X_{32 i}^{4} \\
& \mathrm{PF}_{2 i}^{5}=c_{12}^{5} X_{12 i}^{5}+c_{22}^{5} X_{22 i}^{5}+c_{32}^{5} X_{32 i}^{5}
\end{aligned}
$$

\section{Machine 3:}

$$
\begin{aligned}
& \mathrm{PF}_{3 i}^{1}=c_{13}^{1} X_{13 i}^{1}+c_{23}^{1} X_{23 i}^{1}+c_{33}^{1} X_{33 i}^{1} \\
& \mathrm{PF}_{3 i}^{2}=c_{13}^{2} X_{13 i}^{2}+c_{23}^{2} X_{23 i}^{2}+c_{33}^{2} X_{33 i}^{2} \\
& \mathrm{PF}_{3 i}^{3}=c_{13}^{3} X_{13 i}^{3}+c_{23}^{3} X_{23 i}^{3}+c_{33}^{3} X_{33 i}^{3} \\
& \mathrm{PF}_{3 i}^{4}=c_{13}^{4} X_{13 i}^{4}+c_{23}^{4} X_{23 i}^{4}+c_{33}^{4} X_{33 i}^{4} \\
& \mathrm{PF}_{3 i}^{5}=c_{13}^{5} X_{13 i}^{5}+c_{23}^{5} X_{23 i}^{5}+c_{33}^{5} X_{33 i}^{5}
\end{aligned}
$$

\footnotetext{
${ }^{1}$ Only a subset of jobs are used in calculating the values of the variables. These jobs are called the relevant jobs. The criteria for selecting these relevant jobs are given in Section 3.2.
} 
Machine 4:

$$
\begin{aligned}
& \mathrm{PF}_{4 i}^{1}=c_{14}^{1} X_{14 i}^{1}+c_{24}^{1} X_{24 i}^{1}+c_{34}^{1} X_{34 i}^{1} \\
& \mathrm{PF}_{4 i}^{2}=c_{14}^{2} X_{14 i}^{2}+c_{24}^{2} X_{24 i}^{2}+c_{34}^{2} X_{34 i}^{2} \\
& \mathrm{PF}_{4 i}^{3}=c_{14}^{3} X_{14 i}^{3}+c_{24}^{3} X_{24 i}^{3}+c_{34}^{3} X_{34 i}^{3} \\
& \mathrm{PF}_{4 i}^{4}=c_{14}^{4} X_{14 i}^{4}+c_{24}^{4} X_{24 i}^{4}+c_{34}^{4} X_{34 i}^{4} \\
& \mathrm{PF}_{4 i}^{5}=c_{14}^{5} X_{14 i}^{5}+c_{24}^{5} X_{24 i}^{5}+c_{34}^{5} X_{34 i}^{5}
\end{aligned}
$$

Machine 5:

$$
\begin{aligned}
& \mathrm{PF}_{5 i}^{1}=c_{15}^{1} X_{15 i}^{1}+c_{25}^{1} X_{25 i}^{1}+c_{35}^{1} X_{35 i}^{1} \\
& \mathrm{PF}_{5 i}^{2}=c_{15}^{2} X_{15 i}^{2}+c_{25}^{2} X_{25 i}^{2}+c_{35}^{2} X_{35 i}^{2} \\
& \mathrm{PF}_{5 i}^{3}=c_{15}^{3} X_{15 i}^{3}+c_{25}^{3} X_{25 i}^{3}+c_{35}^{3} X_{35 i}^{3} \\
& \mathrm{PF}_{5 i}^{4}=c_{15}^{4} X_{15 i}^{4}+c_{25}^{4} X_{25 i}^{4}+c_{35}^{4} X_{35 i}^{4} \\
& \mathrm{PF}_{5 i}^{5}=c_{15}^{5} X_{15 i}^{5}+c_{25}^{5} X_{25 i}^{5}+c_{35}^{5} X_{35 i}^{5} .
\end{aligned}
$$

\subsection{Determination of relevant jobs}

In the proposed method, to calculate the values of $X_{1 i j}$ and $X_{2 i j}$ for an arriving job $i$, we use a subset of the jobs instead of all the jobs in the queue. This subset which we call "relevant" jobs are constructed in a slightly different way for each variable and dispatching rule.

All of the jobs are considered to be "relevant" for FCFS. For SPT, only the jobs which have smaller operation times than the arriving job are selected as the "relevant"jobs. For MOD, the following procedure is used: let $k$ be the index for a job waiting at the queue of the machine $j$ and let $i$ be the index for the arriving job. We calculate two priority indices for each job and select job $k$ as "relevant" if its priority index is lower than the job $i$ 's index. The priority index for job $k, I_{k}$, is assigned just as the modified operation due date, whereas the priority index of job $i$ is assigned as the ready time plus a fraction of its total flow allowance. This fraction is calculated by dividing the total processing time until the job $i$ finishes its operation on machine $j$ by the total processing time required for all of its operations.

The above procedures are valid for $X_{2 j i}$. For the variable $X_{2 j i}$, the priority index for job $i$ is calculated in the same way as before except that the jobs residing at the queues of the machines other than the machine $j$ are also considered.

Note that the use of dispatching rule information is quite different in our case than the studies in the literature, i.e., instead of using a separate flowtime estimation model for each rule, we use the same model but redefine the variables for each dispatching rule. For example, when total work load is used as a variable in the model, the total operation times of all the jobs in the queue is calculated for the FCFS rule whereas the total operation time of the jobs with smaller operation times than the arriving job is used for the SPT rule.
Thus, the meaning of the variables in our model is slightly different for each dispatching rule.

\subsection{An illustrative example}

In this section, we explain the proposed method in more detail via an example.

Let us suppose that job $i$ has just arrived at the shop with five machines. Assume that this job has to visit three machines in the following order: Machines 5, 3 and 2. The proposed method estimates the flowtime of this job as

$$
\begin{aligned}
& \mathrm{PF}_{5 i}^{1}=c_{15}^{1} X_{15 i}^{1}+c_{25}^{1} X_{25 i}^{1}+c_{35}^{1} X_{35 i}^{1}, \\
& \mathrm{PF}_{3 i}^{2}=c_{13}^{2} X_{13 i}^{2}+c_{23}^{2} X_{23 i}^{2}+c_{33}^{2} X_{33 i}^{2}, \\
& \mathrm{PF}_{2 i}^{3}=c_{12}^{3} X_{12 i}^{3}+c_{22}^{3} X_{22 i}^{3}+c_{32}^{3} X_{32 i}^{3},
\end{aligned}
$$

When the job arrives to the shop, we collect the values of the $X_{i j}^{k}$ variables and plug them into the equations to obtain the partial flowtimes (PFs) for each operation of the job. The total flowtime of the job $i$ is obtained as:

$F_{i}=\mathrm{PF}_{5 i}^{1}+\mathrm{PF}_{3 i}^{2}+\mathrm{PF}_{2 i}^{3}$.

Note that if the visitation sequence of the job had been Machines 2, 3 and 5, then the flowtime estimate would have been

$F_{i}=\mathrm{PF}_{5 i}^{3}+\mathrm{PF}_{3 i}^{2}+\mathrm{PF}_{2 i}^{1}$.

As can be noted, this new flowtime estimate is quite different than the one given before (Eq. (1.6)). Because the different $\mathrm{PF}$ values are used for the different visitation sequences even though the job visits exactly the same set of machines. This enables us to utilize the route information effectively. Moreover, the distribution of the loads along and outside the route of job $i$ is also captured with the machine and operation specific information provided by the variable $X_{i j}^{k}$. Thus, the first and second motivating points discussed in the introduction section are fully exploited by the proposed method.

Note that the $X_{i j}^{k}$ variables can take different values for each dispatching rule. For example, $X_{1 i j}^{k}$ is the total load of the machine $j$ when the dispatching rule is FCFS. But for the MOD rule, the total load is calculated by summing the operation times of the relevant jobs which have smaller modified operation due dates than job $i$ 's calculated priority index. This property of the proposed method is the third motivating point discussed earlier in the paper.

Finally, machine balance information is utilized explicitly in the proposed method. The machine indexed coefficients carry the necessary machine load information. The equations for the highly utilized machines would have larger coefficient values that results in larger partial flowtime estimates. If all the machines have the same utilization, machine indices would not be needed, and hence the equations would 
reduce to the formulation given by (1.2). This property of the proposed method achieves the objective of the forth motivating point.

\section{Simulation model and experimental conditions}

In this section, we discuss system considerations, simulation model, experimental factors, data collection, and computational requirements.

\subsection{System considerations}

A traditional job shop system is modeled in the SIMAN simulation language [31]. The simulated shop is comprised of five machines. Job arrivals follow a Poisson process. The number of operations of a job is determined from a discrete uniform distribution from 1 to 5 . It is assumed that a particular machine cannot be assigned to more than one operation of a job (i.e., non-reentrant job shop). The jobs are randomly routed in the shop. The operation times are generated from an exponential distribution with the mean of 2.5 time units. Mean utilization (or load) of the shop is adjusted by controlling the job arrival rates.

\subsection{Experimental factors}

In the simulation experiments, four factors are considered: (1) flowtime estimation method, (2) shop load balance, (3) system load (or utilization level), and (4) dispatching rule.

In this study, we test the performance of the following five flowtime estimation methods: (1) operation-based estimation (OBE), (2) total work content (TWK), (3) jobs in queue (JIQ), (4) operation flowtime sampling (OFS), and (5) congestion and operation flowtime sampling (COFS). OBE is the proposed method developed in this study. COFS and OFS are two methods that have demonstrated good performances in the recent studies [6,7]. JIQ is one of the well known methods in the literature [3,8,29], etc. The well known TWK method is also included in this study as the base line rule.

All these methods are tested under two shop conditions: bottleneck and uniform shop environments. Two machine utilization levels are considered. In the uniform job shop environment, the mean system utilization is $65 \%$ and $85 \%$ for the low and high levels, respectively. In the nonuniform (i.e., bottleneck) case, the utilization of the bottleneck machine is set at $75 \%$ for the low level, and $95 \%$ for the high level. The other machines' utilization decrease by $5 \%$ with respect to the bottleneck machine (e.g. $70 \%, 65 \%, 60 \%$ and $55 \%$ for the low level). Note that the average shop utilizations being compared in the balanced and unbalanced cases are the same. These settings are determined based on pilot simulation runs.
We use three dispatching rules in the experiments: first come first served (FCFS), modified operation due date (MOD), and shortest processing time (SPT). These rules are selected because they are most frequently used rules in the literature, each with different characteristics. MOD is a very effective due date oriented rule that assigns priorities that change over time (i.e., dynamic in that sense). On the other hand, static rules assign priorities that do not change over time as long as the job information does not change. SPT is such a rule [3]. This rule is also very effective in reducing flowtimes. FCFS is used as the base line rule in the experiments. This rule is commonly assumed in most analytical model formulations. Besides, it is the preferred rule among practitioners even though several other dispatching rules are strongly recommended by researchers.

\subsection{Performance measures}

We use the following criteria to evaluate the performance of the flowtime estimation methods:

- mean lateness: $\mathrm{ML}=\sum_{i=1}^{n} L_{i} / n$,

- standard deviation of lateness: STDL = $\left(\sum_{i=1}^{n}\left(L_{i}-\bar{L}\right)^{2} / n\right)^{1 / 2}$

- mean tardiness: $\mathrm{MT}=\sum_{i=1}^{n} T_{i} / n$,

- mean squared lateness: MSL $=\sum_{i=1}^{n}(L i)^{2} / n$,

- mean absolute lateness: $\mathrm{MAL}=\sum_{i=1}^{n}\left|L_{i}\right| / n$,

- mean semi-quadratic lateness: $\mathrm{MSQL}=\sum_{i=1}^{n} V_{i} / n$, $V_{i}=L_{i}^{2} \quad$ if $L_{i}>0$, $V_{i}=\left|L_{i}\right| \quad$ if $L_{i} \leq 0$,

- mean flowtime: $\mathrm{MF}=\sum_{i=1}^{n} F_{i} / n$, where $F_{i}$ is the flowtime estimate of job $i, r_{i}$ the release time of job $i, C_{i}$ the completion time of job $i$, Due date of job $i: d_{i}=r_{i}+F_{i}$, Lateness: $L_{i}=C_{i}-d_{i}$, Tardiness: $T_{i}=\max \left(0, C_{i}-d_{i}\right)$, and $n$ the number of jobs completed.

The quality of the flowtime estimator can be determined in terms of accuracy and precision. Vig and Dooley [7] define accuracy of an estimate as the closeness of the individual estimates to their true values and, precision as the variability of the prediction errors. We use ML, MAL and MT to measure the accuracy; and, STDL and MSL to measure the variability of the estimates. MSQL is a hybrid performance criterion and can be a measure of both accuracy and precision.

Even though, MT is a commonly used criterion in the scheduling literature, it is not preferred for flowtime estimation. This is because tardiness is calculated only as the positive lateness. Since ML can lead to misleading results when large negative and positive lateness values cross each other, we use MAL as the accuracy criterion. Besides, MAL is an important performance metric in practice since it measures how close to their due dates jobs are completed. 
$\mathrm{MF}$ is not a commonly used performance indicator for flowtime estimation [6,7]. This is because when FCFS or SPT is used, the flowtime estimation method and the dispatching rule are completely independent. We use MAL and STDL as our primary criteria to measure the accuracy and precision of flowtime estimates. But we also report the statistics for other measures to give a complete picture about the flowtime estimation methods.

\subsection{Data collection and computational requirements}

The computational experiments are carried out in three stages; (1) data collection and estimation of the regression coefficients, (2) comparison of the flowtime estimation methods against various performance measures, and (3) testing the sensitivity of the results to the changes in operating conditions.

At the first stage, the coefficients of flowtime estimation methods are determined for each combination of the experimental factors. For example, 12 sets of coefficients are determined for OBE ( 3 dispatching rules, 2 levels of system balance, and 2 levels of system utilization). The data required for the regression coefficients are collected by taking long simulation runs. A single simulation run is adequate for the dispatching rules which do not rely on due date information (e.g., SPT, FCFS). However, for the due date based rules such as MOD, there must be a mechanism to set due dates which in turns depends on flow allowances. Gee and Smith [8] propose an iterative procedure for this case. According to this method, coefficients are estimated at each iteration and then they become input for the next iteration (i.e. the flow allowances are set by these coefficients at the next iteration). In our study, we use this procedure (with six iterations) to obtain the coefficients. A common random number (CRN) variance reduction technique is also implemented to stabilize the coefficients within the first few iterations.

The regression coefficients are estimated by using the data sets of 160 simulation runs (60 runs for the first iteration of all dispatching rules, and 100 runs for the additional iterations of the MOD dispatching rule). The data is collected during the steady state. Based on pilot runs, the warmup period is set to 20,000 time units (approximately equal to 10,000 job completions). This transient period is determined by taking several replications at different experimental conditions and analyzing the data points with graphical methods. Hence, it is very conservative estimate. At each simulation run, 5000 steady-state observations are collected for each regression equation. In order to achieve independence, observations are collected after every 50 job completions. Hence, each simulation run length consists of 250,000 job completions. This corresponds to about $3 \mathrm{~h}$ of SUN SPARC 2/50 workstations for each run.

The results of extensive simulation experiments and linear regression analysis are summarized in more than 40 tables, but only a representative sample is given in the appendix
(Table 1). During this stage we also made the following observations:

- $R^{2}$ values of all flowtime estimation methods are quite high for the FCFS rule. This indicates that the regression equations estimated for FCFS explain a larger proportion of variation of the flowtimes than the regression equations estimated for other rules (i.e., SPT and MOD). This observation can be attributed to the fact that SPT and MOD create a more dynamic environment in which the shop conditions change rather quickly as compared to FCFS (i.e., dispatching by SPT and MOD creates more variability in the shop due to the changes in the relative ranking of jobs in the queues).

- After a few iterations of the iterative procedure, the coefficients are stabilized for almost all flowtime estimation methods. The only exception is for TWK and JIQ due to fewer factors involved in these rules.

- In the proposed method (OBE), $R^{2}$ values of equations for the earlier operations in the process route (first or second operations of a job) are quite high as compared to $R^{2}$ values of the equations of the later operations, when the dispatching rule is FCFS (i.e., estimating flowtimes for the first few operations of the job is important). Even though the FCFS rule produces low $R^{2}$ values for the later operations, such values are still higher than the ones obtained for SPT and MOD.

- $R^{2}$ values of OFS and COFS are quite high when compared to other methods. This is due to the fourth transformation applied on flowtimes to estimate the coefficients. Weisberg [32] proposes that if the order of transformation is higher than 3 , the models fit very well to the data but serious numerical problems may arise. Neter et al. [33] also claim that when the order is high, one can get a better fit, but it may result in poor interpolation and extrapolations.

- Number of operations parameter of COFS and OFS are sometimes found as the insignificant factor during the flowtime estimation.

At the second stage, we compare the flow time estimation methods by using the coefficients estimated in the previous stage. We implement the method of batch means and run the simulation model for each of 60 design points. Specifically, we take 40 batches of simulation runs, each consisting of 2500 job completions. Thus, each simulation steady state run equals to 100,000 job completions.

Finally, we measure the sensitivity of the results to the changes in arrival rate, machine breakdown events, and processing time variations. During this stage, we take 40 batches of simulation runs each consisting of 2500 job completions (or 100,000 job completions). We replicate these runs for each experimental condition, specifically 120 simulations runs for machine breakdown, 120 runs for processing time variation and 60 runs for load variation, resulting in 300 runs. The results of the 
Table 1

Coefficients, $p$-values and $R^{2}$ values for OBE/FCFS/Unbalanced Shop/High Utilization

\begin{tabular}{|c|c|c|c|c|c|c|c|}
\hline \multicolumn{8}{|c|}{$\mathrm{PF}_{j i}^{k}=c_{1 j}^{k} X_{1 j i}^{k}+c_{2 j}^{k} X_{2 j i}^{k}+c_{3 j}^{k} X_{3 j i}^{k}$} \\
\hline$j k$ & $c_{1 j}^{k}$ & $c_{2 j}^{k}$ & $c_{3 j}^{k}$ & $p_{1 j}^{k}$ & $p_{2 j}^{k}$ & $p_{3 j}^{k}$ & $R^{2}$ \\
\hline 11 & 1.0157 & 0.0452 & 1.1843 & 0.0001 & 0.0001 & 0.0001 & 0.9978 \\
\hline 12 & 0.9846 & 0.1737 & 1.0434 & 0.0001 & 0.0001 & 0.0001 & 0.9816 \\
\hline 13 & 0.9570 & 0.2849 & 0.8153 & 0.0001 & 0.0001 & 0.0001 & 0.9703 \\
\hline 14 & 0.9527 & 0.2977 & 0.8646 & 0.0001 & 0.0001 & 0.0001 & 0.9604 \\
\hline 15 & 0.9387 & 0.3646 & 0.8176 & 0.0001 & 0.0001 & 0.0001 & 0.9530 \\
\hline 21 & 1.0256 & 0.0329 & 1.1859 & 0.0001 & 0.0001 & 0.0001 & 0.9942 \\
\hline 22 & 0.9523 & 0.1289 & 1.0034 & 0.0001 & 0.0001 & 0.0001 & 0.9430 \\
\hline 23 & 0.8998 & 0.1841 & 1.0741 & 0.0001 & 0.0001 & 0.0001 & 0.8960 \\
\hline 24 & 0.8495 & 0.2101 & 1.0938 & 0.0001 & 0.0001 & 0.0001 & 0.8634 \\
\hline 25 & 0.8115 & 0.2472 & 1.1091 & 0.0001 & 0.0001 & 0.0001 & 0.8211 \\
\hline 31 & 1.0388 & 0.0332 & 1.1341 & 0.0001 & 0.0001 & 0.0001 & 0.9865 \\
\hline 32 & 0.8875 & 0.1207 & 1.0425 & 0.0001 & 0.0001 & 0.0001 & 0.8745 \\
\hline 33 & 0.7813 & 0.1562 & 1.0914 & 0.0001 & 0.0001 & 0.0001 & 0.8005 \\
\hline 34 & 0.6556 & 0.2073 & 1.0911 & 0.0001 & 0.0001 & 0.0001 & 0.7198 \\
\hline 35 & 0.5870 & 0.2251 & 1.1451 & 0.0001 & 0.0001 & 0.0001 & 0.6803 \\
\hline 41 & 1.0502 & 0.0292 & 1.1723 & 0.0001 & 0.0001 & 0.0001 & 0.9798 \\
\hline 42 & 0.8472 & 0.1101 & 1.0588 & 0.0001 & 0.0001 & 0.0001 & 0.8233 \\
\hline 43 & 0.6878 & 0.1419 & 1.1672 & 0.0001 & 0.0001 & 0.0001 & 0.7265 \\
\hline 44 & 0.5592 & 0.1618 & 1.2049 & 0.0001 & 0.0001 & 0.0001 & 0.6506 \\
\hline 45 & 0.4482 & 0.1729 & 1.2938 & 0.0001 & 0.0001 & 0.0001 & 0.5962 \\
\hline 51 & 1.0642 & 0.0284 & 1.1204 & 0.0001 & 0.0001 & 0.0001 & 0.9678 \\
\hline 52 & 0.7555 & 0.0904 & 1.1797 & 0.0001 & 0.0001 & 0.0001 & 0.7560 \\
\hline 53 & 0.5923 & 0.1227 & 1.1493 & 0.0001 & 0.0001 & 0.0001 & 0.6576 \\
\hline 54 & 0.4319 & 0.1319 & 1.2748 & 0.0001 & 0.0001 & 0.0001 & 0.5942 \\
\hline 55 & 0.3192 & 0.1284 & 1.4083 & 0.0001 & 0.0001 & 0.0001 & 0.5358 \\
\hline
\end{tabular}

second and third stages are presented in the subsequent sections.

\section{Computational results}

In this section, we present the results of the flowtime estimation methods for various performance criteria (Tables 2 and 3). But the emphasis will be on the primary measures (MAL and STDL). In tables, the first number in each cell represents the result of the balanced case. The second number (or the number in the parenthesis) represents the unbalanced case.

\subsection{Mean absolute lateness (MAL)}

With respect to the MAL criterion, OBE outperforms other flowtime estimation methods (highlighted by the boldface numbers in the tables). We also apply the paired $t$-test to measure the statistical significance between OBE and the next best method at the $5 \%$ alpha level. As shown by " $\star$ ” (indicating that the difference is significant), OBE is better than the other methods. It seems that JIQ exhibits the next closest performance. However, TWK gives the sec- ond best results when the utilization is high and the dispatching rule is SPT. This finding confirms our expectation that processing time is more valuable information than route information when the shop is highly loaded. The other two methods (COFS and OFS) display the poorer performance than TWK.

Among the dispatching rules, MOD produces the lowest MAL values in most of the shop conditions for all the flowtime estimation methods. This is an expected result because MOD utilizes the due date information. The results also indicate that the performance of the flowtime estimation methods deteriorates as the system load increases and/or when the shop is not balanced (i.e. bottleneck situation). In such cases, difference in the relative performance of the flowtime estimation methods is magnified.

We also analyzed the results using ANOVA. As indicated in Table 4, the main factors (flowtime estimation method (F), dispatching rule (D), shop balance (B) and utilization level (U)) are significant at 5\% significance level. We note that the blocking factor (A) which represents experimental conditions is also significant. This indicates that the common random number $(\mathrm{CRN})$ variance reduction technique is quite effective in reducing variability in the experiments. All two-way and higher interactions of factors are also found 
Table 2

Results at low utilization (65\%)

\begin{tabular}{|c|c|c|c|c|c|c|}
\hline $\begin{array}{l}\text { Performance } \\
\text { measure }\end{array}$ & Dispatching rate & OBE & TWK & JIQ & COFS & OFS \\
\hline \multirow[t]{3}{*}{ Mean Lateness } & FCFS & $\begin{array}{l}0.60 \\
(0.86)\end{array}$ & $\begin{array}{l}3.07 \\
(3.45)\end{array}$ & $\begin{array}{l}0.96 \\
(0.92)\end{array}$ & $\begin{array}{l}-1.11 \\
(-1.34)\end{array}$ & $\begin{array}{l}-0.43^{*} \\
\left(-0.28^{*}\right)\end{array}$ \\
\hline & MOD & $\begin{array}{l}0.64 \\
(0.82)\end{array}$ & $\begin{array}{l}0.71 \\
(-\mathbf{0 . 0 6} *)\end{array}$ & $\begin{array}{l}-\mathbf{0 . 0 2}^{*} \\
(-0.28)\end{array}$ & $\begin{array}{l}-0.94 \\
(-1.28)\end{array}$ & $\begin{array}{l}-1.17 \\
(-1.04)\end{array}$ \\
\hline & SPT & $\begin{array}{l}0.97 \\
(1.19)\end{array}$ & $\begin{array}{l}0.36 \\
(0.54)\end{array}$ & $\begin{array}{l}-\mathbf{0 . 2 2}^{*} \\
\left(-\mathbf{0 . 1 3}^{*}\right)\end{array}$ & $\begin{array}{l}-1.40 \\
(-0.73)\end{array}$ & $\begin{array}{l}-1.35 \\
(-0.70)\end{array}$ \\
\hline \multirow[t]{3}{*}{ Std. dev. of lateness } & FCFS & $\begin{array}{l}\text { 6.56* }^{*} \\
\left(6.81^{*}\right)\end{array}$ & $\begin{array}{l}12.35 \\
(14.71)\end{array}$ & $\begin{array}{l}7.86 \\
(8.54)\end{array}$ & $\begin{array}{l}15.72 \\
(17.96)\end{array}$ & $\begin{array}{l}14.74 \\
(16.40)\end{array}$ \\
\hline & MOD & $\begin{array}{l}5.99^{*} \\
\left(7.36^{*}\right)\end{array}$ & $\begin{array}{l}8.00 \\
(10.08)\end{array}$ & $\begin{array}{l}6.59 \\
(8.71)\end{array}$ & $\begin{array}{l}11.59 \\
(13.17)\end{array}$ & $\begin{array}{l}11.90 \\
(13.05)\end{array}$ \\
\hline & SPT & $\begin{array}{l}7.62^{*} \\
\left(9.64^{*}\right)\end{array}$ & $\begin{array}{l}8.70 \\
(11.11)\end{array}$ & $\begin{array}{l}8.21 \\
(10.74)\end{array}$ & $\begin{array}{l}15.22 \\
(16.78)\end{array}$ & $\begin{array}{l}15.18 \\
(16.80)\end{array}$ \\
\hline \multirow[t]{3}{*}{ Mean tardiness } & FCFS & $\begin{array}{l}\text { 2.48* } \\
\left(2.69^{*}\right)\end{array}$ & $\begin{array}{l}6.07 \\
(7.03)\end{array}$ & $\begin{array}{l}3.19 \\
(3.38)\end{array}$ & $\begin{array}{l}4.60 \\
(5.03)\end{array}$ & $\begin{array}{l}4.84 \\
(5.43)\end{array}$ \\
\hline & MOD & $\begin{array}{l}2.15 \\
(2.42)\end{array}$ & $\begin{array}{l}2.77 \\
(2.64)\end{array}$ & $\begin{array}{l}1.97^{*} \\
\left(2.07^{*}\right)\end{array}$ & $\begin{array}{l}2.95 \\
(3.01)\end{array}$ & $\begin{array}{l}2.91 \\
(3.12)\end{array}$ \\
\hline & SPT & $\begin{array}{l}2.75 \\
(3.09)\end{array}$ & $\begin{array}{l}2.86 \\
(3.18)\end{array}$ & $\begin{array}{l}2.40^{*} \\
\left(2.71^{*}\right)\end{array}$ & $\begin{array}{l}3.70 \\
(4.21)\end{array}$ & $\begin{array}{l}3.72 \\
(4.22)\end{array}$ \\
\hline \multirow[t]{3}{*}{$\begin{array}{l}\text { Mean squared } \\
\text { lateness }\end{array}$} & FCFS & $\begin{array}{l}\text { 43.61* } \\
\left(47.35^{*}\right)\end{array}$ & $\begin{array}{l}164.67 \\
(234.18)\end{array}$ & $\begin{array}{l}62.94 \\
(74.14)\end{array}$ & $\begin{array}{l}251.44 \\
(330.73)\end{array}$ & $\begin{array}{l}218.72 \\
(271.02)\end{array}$ \\
\hline & MOD & $\begin{array}{l}36.67^{*} \\
\left(56.25^{*}\right)\end{array}$ & $\begin{array}{l}65.22 \\
(105.27)\end{array}$ & $\begin{array}{l}43.81 \\
(78.76)\end{array}$ & $\begin{array}{l}135.93 \\
(176.04)\end{array}$ & $\begin{array}{l}143.82 \\
(172.63)\end{array}$ \\
\hline & SPT & $\begin{array}{l}\text { 59.68* }^{*} \\
\left(96.61^{*}\right)\end{array}$ & $\begin{array}{l}76.70 \\
(127.75)\end{array}$ & $\begin{array}{l}68.32 \\
(119.20)\end{array}$ & $\begin{array}{l}235.42 \\
(286.21)\end{array}$ & $\begin{array}{l}233.99 \\
(286.62)\end{array}$ \\
\hline \multirow[t]{3}{*}{$\begin{array}{l}\text { Mean absolute } \\
\text { lateness }\end{array}$} & FCFS & $\begin{array}{l}4.37^{*} \\
\left(4.52^{*}\right)\end{array}$ & $\begin{array}{l}9.07 \\
(10.61)\end{array}$ & $\begin{array}{l}5.42 \\
(5.84)\end{array}$ & $\begin{array}{l}10.32 \\
(11.40)\end{array}$ & $\begin{array}{l}10.12 \\
(11.15)\end{array}$ \\
\hline & MOD & $\begin{array}{l}\text { 3.67* } \\
\left(4.02^{*}\right)\end{array}$ & $\begin{array}{l}4.82 \\
(5.34)\end{array}$ & $\begin{array}{l}3.96 \\
(4.41)\end{array}$ & $\begin{array}{l}6.87 \\
(7.29)\end{array}$ & $\begin{array}{l}6.98 \\
(7.28)\end{array}$ \\
\hline & SPT & $\begin{array}{l}4.54^{*} \\
\left(83.78^{*}\right)\end{array}$ & $\begin{array}{l}5.36 \\
(107.52)\end{array}$ & $\begin{array}{l}5.02 \\
(100.75)\end{array}$ & $\begin{array}{l}8.80 \\
(114.63)\end{array}$ & $\begin{array}{l}8.79 \\
(115.93)\end{array}$ \\
\hline \multirow[t]{3}{*}{$\begin{array}{l}\text { Mean semi-quadratic } \\
\text { lateness }\end{array}$} & FCFS & $\begin{array}{l}\text { 29.38* } \\
\left(32.91^{*}\right)\end{array}$ & $\begin{array}{l}132.15 \\
(188.75)\end{array}$ & $\begin{array}{l}44.93 \\
(51.94)\end{array}$ & $\begin{array}{l}74.00 \\
(91.22)\end{array}$ & $\begin{array}{l}82.96 \\
(109.73)\end{array}$ \\
\hline & MOD & $\begin{array}{l}29.63^{*} \\
\left(47.31^{*}\right)\end{array}$ & $\begin{array}{l}51.09 \\
(82.81)\end{array}$ & $\begin{array}{l}33.68 \\
(65.11)\end{array}$ & $\begin{array}{l}40.86 \\
(53.14)\end{array}$ & $\begin{array}{l}40.44 \\
(62.43)\end{array}$ \\
\hline & SPT & $\begin{array}{l}\text { 49.99* } \\
\left(83.78^{*}\right)\end{array}$ & $\begin{array}{l}58.37 \\
(107.52)\end{array}$ & $\begin{array}{l}52.34 \\
(100.75)\end{array}$ & $\begin{array}{l}68.25 \\
(114.63)\end{array}$ & $\begin{array}{l}69.10 \\
(115.93)\end{array}$ \\
\hline \multirow[t]{3}{*}{ Mean flowtime } & FCFS & $\begin{array}{l}19.44 \\
(21.37)\end{array}$ & $\begin{array}{l}19.44 \\
(21.37)\end{array}$ & $\begin{array}{l}19.44 \\
(21.37)\end{array}$ & $\begin{array}{l}19.44 \\
(21.37)\end{array}$ & $\begin{array}{l}19.44 \\
(21.37)\end{array}$ \\
\hline & MOD & $\begin{array}{l}14.78 \\
(15.55)\end{array}$ & $\begin{array}{l}14.57 \\
(15.30)\end{array}$ & $\begin{array}{l}14.90 \\
(15.67)\end{array}$ & $\begin{array}{l}15.37 \\
(16.23)\end{array}$ & $\begin{array}{l}15.32 \\
(16.15)\end{array}$ \\
\hline & SPT & $\begin{array}{l}14.28 \\
(14.87)\end{array}$ & $\begin{array}{l}14.28 \\
(14.87)\end{array}$ & $\begin{array}{l}14.28 \\
(14.87)\end{array}$ & $\begin{array}{l}14.28 \\
(14.87)\end{array}$ & $\begin{array}{l}14.28 \\
(14.87)\end{array}$ \\
\hline
\end{tabular}

\footnotetext{
${ }^{*}$ Statistically significant at $5 \%$.
} 
Table 3

Results at high utilization (85\%)

\begin{tabular}{|c|c|c|c|c|c|c|}
\hline $\begin{array}{l}\text { Performance } \\
\text { measure }\end{array}$ & Dispatching rate & OBE & TWK & JIQ & COFS & OFS \\
\hline \multirow[t]{3}{*}{ Mean lateness } & FCFS & $\begin{array}{l}0.42 \\
\left(0.39^{*}\right)\end{array}$ & $\begin{array}{l}9.24 \\
(15.59)\end{array}$ & $\begin{array}{l}1.26 \\
(1.34)\end{array}$ & $\begin{array}{l}-0.62 \\
(-2.61)\end{array}$ & $\begin{array}{l}1.31 \\
(3.68)\end{array}$ \\
\hline & MOD & $\begin{array}{l}0.72 \\
(-2.46)\end{array}$ & $\begin{array}{l}-1.02 \\
(-0.70)\end{array}$ & $\begin{array}{l}-1.92 \\
(-2.77)\end{array}$ & $\begin{array}{l}-0.19 \\
(\mathbf{0 . 3 0})\end{array}$ & $\begin{array}{l}-\mathbf{0 . 1 7} \\
(1.26)\end{array}$ \\
\hline & SPT & $\begin{array}{l}-1.21 \\
(-2.26)\end{array}$ & $\begin{array}{l}-1.04 \\
\left(-\mathbf{1 . 8 5}^{*}\right)\end{array}$ & $\begin{array}{l}-1.90 \\
(-4.02)\end{array}$ & $\begin{array}{l}\mathbf{0 . 2 7} * \\
(2.02)\end{array}$ & $\begin{array}{l}0.39 \\
(2.15)\end{array}$ \\
\hline \multirow[t]{3}{*}{ Std. dev. of lateness } & FCFS & $\begin{array}{l}11.36^{*} \\
\left(12.59^{*}\right)\end{array}$ & $\begin{array}{l}29.89 \\
(43.84)\end{array}$ & $\begin{array}{l}13.87 \\
(16.27)\end{array}$ & $\begin{array}{l}24.83 \\
(36.37)\end{array}$ & $\begin{array}{l}24.07 \\
(35.61)\end{array}$ \\
\hline & MOD & $\begin{array}{l}12.17^{*} \\
\left(27.94^{*}\right)\end{array}$ & $\begin{array}{l}19.71 \\
(47.59)\end{array}$ & $\begin{array}{l}16.38 \\
(42.49)\end{array}$ & $\begin{array}{l}18.51 \\
(40.34)\end{array}$ & $\begin{array}{l}20.00 \\
(43.51)\end{array}$ \\
\hline & SPT & $\begin{array}{l}22.50^{*} \\
\left(49.05^{*}\right)\end{array}$ & $\begin{array}{l}25.51 \\
(58.56)\end{array}$ & $\begin{array}{l}25.46 \\
(64.59)\end{array}$ & $\begin{array}{l}30.86 \\
(62.15)\end{array}$ & $\begin{array}{l}30.94 \\
(62.28)\end{array}$ \\
\hline \multirow[t]{3}{*}{ Mean tardiness } & FCFS & $\begin{array}{l}\text { 4.03* }^{*} \\
\left(3.04^{*}\right)\end{array}$ & $\begin{array}{l}16.42 \\
(5.57)\end{array}$ & $\begin{array}{l}5.54 \\
(4.15)\end{array}$ & $\begin{array}{l}8.49 \\
(5.61)\end{array}$ & $\begin{array}{l}9.53 \\
(6.33)\end{array}$ \\
\hline & MOD & $\begin{array}{l}\text { 2.17* } \\
\left(3.04^{*}\right)\end{array}$ & $\begin{array}{l}3.60 \\
(5.57)\end{array}$ & $\begin{array}{l}2.47 \\
(4.15)\end{array}$ & $\begin{array}{l}4.03 \\
(5.61)\end{array}$ & $\begin{array}{l}4.26 \\
(6.33)\end{array}$ \\
\hline & SPT & $\begin{array}{l}4.46^{*} \\
\left(6.55^{*}\right)\end{array}$ & $\begin{array}{l}5.01 \\
(7.32)\end{array}$ & $\begin{array}{l}4.71 \\
(10.25)\end{array}$ & $\begin{array}{l}7.31 \\
(10.35)\end{array}$ & $\begin{array}{l}7.38 \\
(10.42)\end{array}$ \\
\hline \multirow[t]{3}{*}{$\begin{array}{l}\text { Mean squared } \\
\text { lateness }\end{array}$} & FCFS & $\begin{array}{l}130.94^{*} \\
\left(165.19^{*}\right)\end{array}$ & $\begin{array}{l}1028.64 \\
(2587.75)\end{array}$ & $\begin{array}{l}195.96 \\
(274.82)\end{array}$ & $\begin{array}{l}634.70 \\
(1567.49)\end{array}$ & $\begin{array}{l}589.08 \\
(1409.42)\end{array}$ \\
\hline & MOD & $\begin{array}{l}159.34^{*} \\
\left(1132.58^{*}\right)\end{array}$ & $\begin{array}{l}420.18 \\
(3312.89)\end{array}$ & $\begin{array}{l}290.33 \\
(2659.13)\end{array}$ & $\begin{array}{l}354.03 \\
(2247.65)\end{array}$ & $\begin{array}{l}414.92 \\
(2598.84)\end{array}$ \\
\hline & SPT & $\begin{array}{l}535.65^{*} \\
\left(15.36^{*}\right)\end{array}$ & $\begin{array}{l}691.62 \\
(16.48)\end{array}$ & $\begin{array}{l}691.14 \\
(24.52)\end{array}$ & $\begin{array}{l}987.48 \\
(18.69)\end{array}$ & $\begin{array}{l}991.32 \\
(18.69)\end{array}$ \\
\hline \multirow[t]{3}{*}{$\begin{array}{l}\text { Mean absolute } \\
\text { lateness }\end{array}$} & FCFS & $\begin{array}{l}7.64^{*} \\
\left(94.07^{*}\right)\end{array}$ & $\begin{array}{l}23.60 \\
(2130.42)\end{array}$ & $\begin{array}{l}9.82 \\
(174.83)\end{array}$ & $\begin{array}{l}17.60 \\
(468.89)\end{array}$ & $\begin{array}{l}17.76 \\
(900.17)\end{array}$ \\
\hline & MOD & $\begin{array}{l}\text { 5.03* }^{*} \\
\left(\mathbf{8 . 5 4}^{*}\right)\end{array}$ & $\begin{array}{l}8.21 \\
(11.85)\end{array}$ & $\begin{array}{l}6.86 \\
(11.08)\end{array}$ & $\begin{array}{l}8.26 \\
(10.93)\end{array}$ & $\begin{array}{l}8.68 \\
(11.41)\end{array}$ \\
\hline & SPT & $\begin{array}{l}\text { 10.14* } \\
\left(3139.04^{*}\right)\end{array}$ & $\begin{array}{l}11.05 \\
(4691.55)\end{array}$ & $\begin{array}{l}11.33 \\
(5414.94)\end{array}$ & $\begin{array}{l}14.36 \\
(5014.48)\end{array}$ & $\begin{array}{l}14.37 \\
(5030.09)\end{array}$ \\
\hline \multirow[t]{3}{*}{$\begin{array}{l}\text { Mean semi-quadratic } \\
\text { lateness }\end{array}$} & FCFS & $\begin{array}{l}\text { 75.66* }^{*} \\
\left(94.07^{*}\right)\end{array}$ & $\begin{array}{l}798.74 \\
(2130.42)\end{array}$ & $\begin{array}{l}126.91 \\
(174.83)\end{array}$ & $\begin{array}{l}246.26 \\
(468.89)\end{array}$ & $\begin{array}{l}317.60 \\
(900.17)\end{array}$ \\
\hline & MOD & $\begin{array}{l}140.02^{*} \\
\left(1025.48^{*}\right)\end{array}$ & $\begin{array}{l}350.93 \\
(3198.49)\end{array}$ & $\begin{array}{l}246.09 \\
(2556.11)\end{array}$ & $\begin{array}{l}219.65 \\
(2005.43)\end{array}$ & $\begin{array}{l}246.33 \\
(2356.47)\end{array}$ \\
\hline & SPT & $\begin{array}{l}411.60^{*} \\
\left(2625.94^{*}\right)\end{array}$ & $\begin{array}{l}598.06 \\
(4505.78)\end{array}$ & $\begin{array}{l}600.97 \\
(4880.54)\end{array}$ & $\begin{array}{l}617.15 \\
(4413.72)\end{array}$ & $\begin{array}{l}626.81 \\
(4434.25)\end{array}$ \\
\hline \multirow[t]{3}{*}{ Mean flowtime } & FCFS & $\begin{array}{l}45.30 \\
(63.09)\end{array}$ & $\begin{array}{l}45.30 \\
(63.09)\end{array}$ & $\begin{array}{l}45.30 \\
(63.09)\end{array}$ & $\begin{array}{l}45.30 \\
(63.09)\end{array}$ & $\begin{array}{l}45.30 \\
(63.09)\end{array}$ \\
\hline & MOD & $\begin{array}{l}26.58 \\
(33.41)\end{array}$ & $\begin{array}{l}24.74 \\
(30.20)\end{array}$ & $\begin{array}{l}26.61 \\
(33.15)\end{array}$ & $\begin{array}{l}26.40 \\
(32.46)\end{array}$ & $\begin{array}{l}26.23 \\
(31.59)\end{array}$ \\
\hline & SPT & $\begin{array}{l}22.27 \\
(26.07)\end{array}$ & $\begin{array}{l}22.27 \\
(26.07)\end{array}$ & $\begin{array}{l}22.27 \\
(26.07)\end{array}$ & $\begin{array}{l}22.27 \\
(26.07)\end{array}$ & $\begin{array}{l}22.27 \\
(26.07)\end{array}$ \\
\hline
\end{tabular}

${ }^{*}$ Statistically significant at $5 \%$. 
Table 4

Analysis of variance

\begin{tabular}{|c|c|c|c|c|}
\hline Source & $\mathrm{DF}$ & Sum of squares & F value & Pr gt F \\
\hline \multicolumn{5}{|c|}{ Mean absolute lateness } \\
\hline Model & 98 & 103532.844689 & 167.94 & 0.0001 \\
\hline Error & 2301 & 14475.054701 & & \\
\hline A & 39 & 4508.8870716 & 18.38 & 0.0001 \\
\hline $\mathrm{F}$ & 4 & 13507.6697131 & 536.81 & 0.0001 \\
\hline $\mathrm{D}$ & 2 & 15137.8065276 & 1203.18 & 0.0001 \\
\hline B & 1 & 5265.7548754 & 837.06 & 0.0001 \\
\hline $\mathrm{U}$ & 1 & 33835.4790550 & 5378.59 & 0.0001 \\
\hline $\mathrm{F} * \mathrm{D}$ & 8 & 11588.6314787 & 230.27 & 0.0001 \\
\hline $\mathrm{F} * \mathrm{~B}$ & 4 & 338.5049736 & 13.45 & 0.0001 \\
\hline $\mathrm{F} * \mathrm{U}$ & 4 & 2409.7964481 & 95.77 & 0.0001 \\
\hline $\mathrm{D} * \mathrm{~B}$ & 2 & 361.4696643 & 28.73 & 0.0001 \\
\hline $\mathrm{D}^{*} \mathrm{U}$ & 2 & 4748.8748836 & 377.45 & 0.0001 \\
\hline$B * U$ & 1 & 3466.1594554 & 550.99 & 0.0001 \\
\hline $\mathrm{F} * \mathrm{D} * \mathrm{~B}$ & 8 & 1468.6904112 & 29.18 & 0.0001 \\
\hline $\mathrm{F} * \mathrm{D} * \mathrm{U}$ & 8 & 5284.0927552 & 105.00 & 0.0001 \\
\hline $\mathrm{F} * \mathrm{~B} * \mathrm{U}$ & 4 & 229.8215686 & 9.13 & 0.0001 \\
\hline $\mathrm{D} * \mathrm{~B} * \mathrm{U}$ & 2 & 277.2954482 & 22.04 & 0.0001 \\
\hline $\mathrm{F} * \mathrm{D} * \mathrm{~B} * \mathrm{U}$ & 8 & 1103.9103597 & 21.94 & 0.0001 \\
\hline \multicolumn{5}{|c|}{ Standard deviation of lateness } \\
\hline A & 39 & 86632.500732 & 16.50 & 0.0001 \\
\hline $\mathrm{F}$ & 4 & 41043.803271 & 76.21 & 0.0001 \\
\hline $\mathrm{D}$ & 2 & 40280.073090 & 149.57 & 0.0001 \\
\hline B & 1 & 79176.330130 & 588.02 & 0.0001 \\
\hline $\mathrm{U}$ & 1 & 267204.708797 & 1984.45 & 0.0001 \\
\hline $\mathrm{F} * \mathrm{D}$ & 8 & 12194.895406 & 11.32 & 0.0001 \\
\hline $\mathrm{F} * \mathrm{~B}$ & 4 & 2217.584826 & 4.12 & 0.0025 \\
\hline $\mathrm{F}^{*} \mathrm{U}$ & 4 & 7896.206921 & 14.66 & 0.0001 \\
\hline $\mathrm{D}^{*} \mathrm{~B}$ & 2 & 15610.863893 & 57.97 & 0.0001 \\
\hline $\mathrm{D}^{*} \mathrm{U}$ & 2 & 35011.285724 & 130.01 & 0.0001 \\
\hline$B * U$ & 1 & 57411.829662 & 426.38 & 0.0001 \\
\hline $\mathrm{F} * \mathrm{D} * \mathrm{~B}$ & 8 & 1518.875345 & 1.41 & 0.1870 \\
\hline $\mathrm{F}^{*} \mathrm{D} * \mathrm{U}$ & 8 & 4719.294630 & 4.38 & 0.0001 \\
\hline $\mathrm{F}^{*} \mathrm{~B} * \mathrm{U}$ & 4 & 1574.983285 & 2.92 & 0.0200 \\
\hline $\mathrm{D} * \mathrm{~B} * \mathrm{U}$ & 2 & 14211.381096 & 52.77 & 0.0001 \\
\hline $\mathrm{F} * \mathrm{D} * \mathrm{~B} * \mathrm{U}$ & 8 & 926.740971 & 0.86 & 0.5495 \\
\hline
\end{tabular}

A: block effect, F: flowtime estimation method, D: dispatching rule, B: shop balance, U: utilization

to be significant. An analysis of these interactions indicate that increasing the system load significantly affects the performance of the methods regardless of the dispatching rule in use. We note that some flowtime estimation methods are more sensitive to the system load level than others. For example, the performance of TWK deteriorates much more, when the dispatching rule is FCFS and MOD. In the SPT case, however, JIQ is affected more than any other method. In general, OBE is quite robust to the changes in the system load.

The analysis of the flowtime estimation method and the shop balance interaction indicate that deterioration of the shop balance negatively influences the MAL criterion. This influence is rather modest when the shop is lightly loaded. However, the effect is magnified in the highly loaded environment. This agrees with previous research [6,7,28]. It can also be noted that JIQ is affected more than any other method with the SPT rule in the high utilization case. This means that JIQ reacts more nervously to the changes of the shop balance and system load when the dispatching rule is SPT. In order to identify the differences of the flowtime estimation methods, we applied Duncan's Multiple Range test for the main effects of the factors. The results are given in Table 5. In this table, $N$ represents the number of observations and the methods are grouped by levels and each level is represented by a letter. The levels which are statistically 
Table 5

Duncan's multiple range tests for MAL

\begin{tabular}{|c|c|c|c|c|c|c|c|}
\hline \multicolumn{4}{|c|}{ MAL Performance } & \multicolumn{4}{|c|}{ STDL Performance } \\
\hline Levels & Mean & $N$ & Method & Levels & Mean & $N$ & Method \\
\hline \multicolumn{8}{|c|}{ All factors included } \\
\hline A & 12.5706 & 480 & OFS & A & 25.4546 & 480 & OFS \\
\hline A & 12.3921 & 480 & COFS & A & 25.3725 & 480 & COFS \\
\hline A & 12.3598 & 480 & TWK & A & 24.1703 & 480 & TWK \\
\hline B & 8.7746 & 480 & JIQ & $\mathrm{B}$ & 19.1416 & 480 & JIQ \\
\hline $\mathrm{C}$ & 6.7764 & 480 & OBE & $\mathrm{C}$ & 14.9658 & 480 & OBE \\
\hline \multicolumn{8}{|c|}{ Utilization $=65 \%$} \\
\hline A & 8.96967 & 240 & COFS & $\mathrm{A}$ & 15.07308 & 240 & COFS \\
\hline A & 8.90987 & 240 & OFS & B & 14.67967 & 240 & OFS \\
\hline B & 6.83592 & 240 & TWK & $\mathrm{C}$ & 10.82333 & 240 & TWK \\
\hline $\mathrm{C}$ & 5.03192 & 240 & JIQ & $\mathrm{D}$ & 8.44104 & 240 & JIQ \\
\hline $\mathrm{D}$ & 4.35242 & 240 & OBE & $\mathrm{E}$ & 7.32979 & 240 & OBE \\
\hline \multicolumn{8}{|c|}{ Utilization $=85 \%$} \\
\hline A & 17.8838 & 240 & TWK & $\mathrm{A}$ & 37.517 & 240 & TWK \\
\hline B & 16.2313 & 240 & OFS & A & 36.229 & 240 & OFS \\
\hline B & 15.8146 & 240 & COFS & A & 35.672 & 240 & COFS \\
\hline $\mathrm{C}$ & 12.5173 & 240 & JIQ & B & 29.842 & 240 & JIQ \\
\hline $\mathrm{D}$ & 9.2003 & 240 & OBE & $\mathrm{C}$ & 22.602 & 240 & OBE \\
\hline \multicolumn{8}{|c|}{ Balanced shop } \\
\hline A & 11.11608 & 240 & OFS & A & 19.4736 & 240 & OFS \\
\hline A & 11.03367 & 240 & COFS & A & 19.4573 & 240 & COFS \\
\hline B & 10.35300 & 240 & TWK & B & 17.3600 & 240 & TWK \\
\hline $\mathrm{C}$ & 7.06763 & 240 & JIQ & $\mathrm{C}$ & 13.0612 & 240 & JIQ \\
\hline $\mathrm{D}$ & 5.89696 & 240 & OBE & $\mathrm{D}$ & 11.0341 & 240 & $\mathrm{OBE}$ \\
\hline \multicolumn{8}{|c|}{ Unbalanced shop } \\
\hline A & 14.3667 & 240 & TWK & A & 31.436 & 240 & OFS \\
\hline BA & 14.0250 & 240 & OFS & A & 31.288 & 240 & COFS \\
\hline B & 13.7506 & 240 & COFS & A & 30.981 & 240 & TWK \\
\hline $\mathrm{C}$ & 10.4816 & 240 & JIQ & $\mathrm{B}$ & 25.222 & 240 & JIQ \\
\hline $\mathrm{D}$ & 7.6557 & 240 & OBE & $\mathrm{C}$ & 18.897 & 240 & OBE \\
\hline
\end{tabular}

different from each other at a significance level of 5\% are labeled with different letters. The methods are also ranked from the worst to the best. The results indicate that $\mathrm{OBE}$ is the best and JIQ is the next best flowtime estimation method for the MAL measure. OFS, COFS and TWK are grouped to the same level indicating no statistical difference between them. However, the relative ranking of these methods change when the shop conditions (balance or utilization) are set to different levels.

\subsection{Standard deviation of lateness}

As discussed earlier in the paper, this criterion is used to assess the precision of the flowtime estimation methods.

From the results summarized in Tables 2 and 3, OBE is again the best flowtime estimation method. This is also verified by the results of the paired $t$-test. It appears that JIQ is the second best except for the case in which the shop is highly loaded and the dispatching rule is SPT. COFS and OFS still display poor performance. However, COFS becomes the third best method in conjunction with the MOD rule when the shop load is high. Among the dispatching rules, FCFS yields the best STDL values whereas SPT is the worst. This is again due to the dynamic nature of the SPT rule that increases variability in the system. As was also observed by Schultz [34], SPT results in very long waiting times for some jobs when compared with FCFS. This problem can be alleviated by using the truncated version of SPT (i.e., increase the priority of a job which is in the queue for more a certain amount of time). Similar to MAL, an increase in the system load and/or deterioration in machine load balance negatively affects the STDL performance and 
magnifies differences between the flowtime estimation methods.

The ANOVA results (Table 4) indicate that all the main factors and the blocking factor are significant. Most of the two-way and three-way interactions are also significant. By examining these interactions, we note that the system load has adverse affects on the performance of the flowtime estimation methods; TWK is most affected method when the dispatching rule is FCFS and MOD. When the rule is SPT and the shop is unbalanced, the performance of JIQ deteriorates more than any other method as a result of the increased system load. The results also indicate that shop balance considerably affects the STDL performance of the flowtime methods. We observe that the impact of the shop balance is minimum for OBE and JIQ in conjunction with the FCFS rule. With the other rules, impact of the balance on the flowtimes estimation methods is nearly the same. According to Duncan's multiple range test results (Table 5), OBE is again the best rule and is followed by JIQ, TWK, COFS and OFS. In general, COFS and OFS display very poor performance.

\subsection{Other performance measures}

The results for other performance measures are also given in Tables 2 and 3. These are: mean lateness (ML), mean tardiness (MT), mean squared lateness (MSL), mean semi-quadratic lateness (MSQL), and mean flowtime (MF). General observations are as follows:

- There is no definite best method for the ML criterion. OBE is the best when used with FCFS at the high utilization. In other cases, the relative performance of the methods change as the experimental conditions vary. We note that OFS and COFS which were worst with respect to MAL and STDL, now display better performance.

- In the tardiness case, when the dispatching rule is FCFS, $\mathrm{OBE}$ is the best. However, when dispatching rule is either MOD or SPT, OBE yields the best performance only at the high system load level. At the low load case, however, JIQ is slightly better than OBE. This improved performance of JIQ is partly due to the fact that it overestimates the flowtimes of the jobs and consequently it results in early job completions with small tardiness values. This is verified by the negative ML values obtained for JIQ.

- As expected, the results for MSL are similar to the STDL case since both measures aim to quantify the variability of lateness.

- MSQL displays a mixed behavior of MAL and MSL since it is a combination of these two measures. Also note that when ML takes negative values, MSQL takes quite smaller values. This is because MSQL penalizes the early jobs only with the absolute value of the earliness whereas it penalizes the late jobs with the square of the lateness.

- Another observation is that exactly the same MF values are obtained for each flowtime estimation method when the dispatching rule is FCFS and SPT. This is proba- bly due to the use of common random numbers and the rules FCFS and SPT which do not utilize any flowtime allowance information.

\section{Sensitivity analysis}

In addition to the standard conditions discussed above, we also test the methods for changing shop conditions such as machine breakdowns, processing time variation, and load variation. Here, we do not develop new regression equations for the flowtime estimation methods. Instead, we use the coefficients obtained at the first stage experiments.

\subsection{Machine breakdown}

Machine breakdowns are modeled using the busy time approach proposed by Law and Kelton [35] who recommend that the following gamma distributions can be used for busy time distribution and down time distribution in the absence of data:

busy time distribution:

$\operatorname{Gamma}\left(\alpha_{\mathrm{b}}=0.7, \beta_{\mathrm{b}}=d_{\mathrm{avg}} \times \varepsilon / 0.7(1-\varepsilon)\right)$,

\section{down time distribution:}

$\operatorname{Gamma}\left(\alpha_{\mathrm{d}}=1.4, \beta_{\mathrm{d}}=d_{\mathrm{avg}} / 1.4\right)$,

where $\alpha_{\mathrm{b}}$ and $\beta_{\mathrm{b}}$ are the shape and scale parameters of the busy time distribution, $d_{\text {avg }}$ is mean duration of the down times and $\varepsilon$ is efficiency level (long-run ratio of the machine busy time to total busy and down times). We use two levels of the mean duration of breakdowns (or, mean down time), $d_{\text {avg }}=5 p_{\text {avg }}$ and $d_{\text {avg }}=15 p_{\text {avg }}$, where $p_{\text {avg }}$ is the average operation time. For efficiency, we again use two levels: $\varepsilon=80 \%$ and $90 \%$. By changing the mean down time for each efficiency level, we obtain two different cases. In the former case, machines are broken down frequently but repaired quickly (i.e., $d_{\text {avg }}=5 p_{\text {avg }}$ ). In the latter case, the frequency of the breakdowns is smaller but the mean down time is much larger than the former case (i.e., $d_{\mathrm{avg}}=15 p_{\mathrm{avg}}$ ).

Even though the simulation runs are made at every experimental condition, the system saturates (i.e., the system becomes unstable) at high utilization rates even for the low machine breakdowns. For that reason, the results are presented for only the low utilization case. Furthermore, because of the space limitation, we give the results with the MOD rule.

First, as displayed in Tables 6-8, the performance of the flowtime estimation methods deteriorates for all shop conditions as the efficiency level (e) is decreased (i.e., more frequent breakdowns are allowed to occur). Moreover, we observe that increasing the mean duration of breakdowns (e.g., $d=15 p$ ) negatively affects the performance of the all the methods for all criteria. It seems that the well known TWK method is the most sensitive method to the changes in the efficiency level in the system. This is because TWK 
Table 6

Machine breakdown results for MOD at low utilization

\begin{tabular}{|c|c|c|c|c|c|c|c|c|c|}
\hline$\varepsilon$ & $d$ level & Methods & ML & STDL & MT & MSL & MAL & MSQL & MF \\
\hline \multicolumn{10}{|c|}{ Balanced shop } \\
\hline \multirow{10}{*}{$90 \%$} & $d=5 \mathrm{p}$ & OBE & 4.40 & $11.19^{*}$ & 5.50 & $145.75^{*}$ & 6.60 & 140.12 & 21.03 \\
\hline & & TWK & 6.55 & 14.64 & 7.63 & 261.97 & 8.71 & 255.67 & $20.41^{*}$ \\
\hline & & JIQ & 3.55 & 12.19 & 5.10 & 163.59 & 6.65 & 155.26 & 21.31 \\
\hline & & COFS & -1.51 & 15.78 & $4.02^{*}$ & 252.11 & 9.55 & 92.50 & 22.64 \\
\hline & & OFS & $-1.18^{*}$ & 15.99 & 4.16 & 258.92 & 9.50 & 99.92 & 22.55 \\
\hline & $d=15 \mathrm{p}$ & OBE & 7.28 & $18.07^{*}$ & 8.55 & 381.73 & 9.82 & 373.87 & 25.78 \\
\hline & & TWK & 11.07 & 22.66 & 12.15 & 640.29 & 13.23 & 633.82 & 24.93* \\
\hline & & JIQ & 6.04 & 18.65 & 7.91 & 386.43 & 9.78 & 373.92 & 26.34 \\
\hline & & COFS & -1.27 & 22.80 & $6.27^{*}$ & 523.71 & 13.82 & 243.00 & 28.23 \\
\hline & & OFS & $0.09^{*}$ & 22.76 & 6.84 & 520.03 & 13.59 & 274.12 & 27.84 \\
\hline \multirow[t]{10}{*}{$80 \%$} & $d=5 \mathrm{p}$ & OBE & 9.92 & 21.09 & 10.63 & 559.27 & 11.33 & 555.35 & 30.52 \\
\hline & & TWK & 15.50 & 28.08 & 15.93 & 1061.49 & 16.37 & 1059.51 & $29.37^{*}$ \\
\hline & & JIQ & 8.98 & 23.54 & 10.10 & 651.80 & 11.43 & 645.41 & 31.28 \\
\hline & & COFS & -2.47 & $19.99^{*}$ & $4.64^{*}$ & 411.48 & 11.75 & $178.34^{*}$ & 34.98 \\
\hline & & OFS & $0.27^{*}$ & 20.75 & 5.59 & 437.84 & 11.45 & 251.90 & 33.93 \\
\hline & $d=15 \mathrm{p}$ & OBE & 16.13 & 28.80 & 17.05 & 1099.93 & 17.97 & 1092.99 & 40.51 \\
\hline & & TWK & 25.35 & 38.22 & 25.79 & 2133.03 & 26.22 & 2131.03 & $39.22 *$ \\
\hline & & JIQ & 14.26 & 30.35 & 15.79 & 1137.68 & 17.32 & 1125.44 & 41.81 \\
\hline & & COFS & -2.93 & 27.69 & $7.52^{*}$ & 778.99 & 17.97 & $342.67^{*}$ & 46.70 \\
\hline & & OFS & $1.90^{*}$ & 27.36 & 9.52 & 756.32 & 17.14 & 478.15 & 45.40 \\
\hline \multicolumn{10}{|c|}{ Unbalanced shop } \\
\hline \multirow[t]{10}{*}{$90 \%$} & $d=5 \mathrm{p}$ & OBE & 4.84 & $15.02^{*}$ & 6.04 & 258.02* & $7.24^{*}$ & 250.02 & 22.77 \\
\hline & & TWK & 6.64 & 20.95 & 8.02 & 508.47 & 9.40 & 498.81 & $22.00^{*}$ \\
\hline & & JIQ & 3.90 & 18.19 & 5.69 & 368.56 & 7.48 & 357.73 & 23.05 \\
\hline & & COFS & -1.45 & 18.51 & $4.34^{*}$ & 350.91 & 10.13 & $159.37^{*}$ & 24.72 \\
\hline & & OFS & $-0.50^{*}$ & 18.54 & 4.73 & 351.39 & 9.95 & 194.15 & 24.26 \\
\hline & $d=15 \mathrm{p}$ & OBE & 7.84 & $21.15^{*}$ & 9.22 & 517.93* & 10.60 & 506.51 & 27.84 \\
\hline & & TWK & 11.31 & 27.04 & 12.67 & 878.88 & 14.02 & 869.29 & $26.67^{*}$ \\
\hline & & JIQ & 6.47 & 23.33 & 8.56 & 600.11 & 10.65 & 585.02 & 28.09 \\
\hline & & COFS & -1.01 & 24.27 & $6.52^{*}$ & 593.66 & 14.05 & $294.21^{*}$ & 30.35 \\
\hline & & OFS & $0.81^{*}$ & 24.28 & 7.33 & 595.29 & 13.84 & 364.82 & 29.99 \\
\hline \multirow[t]{10}{*}{$80 \%$} & $d=5 \mathrm{p}$ & OBE & 14.29 & 82.98 & 15.29 & 10979.27 & 16.28 & 10965.42 & 41.02 \\
\hline & & TWK & 22.45 & 101.83 & 22.96 & 17728.16 & 23.46 & 17725.50 & $37.81^{*}$ \\
\hline & & JIQ & 13.67 & 91.88 & 15.38 & 12400.27 & 17.09 & 12384.94 & 41.08 \\
\hline & & COFS & $-0.74^{*}$ & $61.47^{*}$ & $8.36^{*}$ & $6033.46^{*}$ & 17.46 & $5567.01^{*}$ & 48.34 \\
\hline & & OFS & 5.45 & 86.03 & 12.11 & 12450.21 & 18.77 & 12128.56 & 47.02 \\
\hline & $d=15 \mathrm{p}$ & OBE & 20.27 & 77.98 & 21.42 & 10216.06 & 22.57 & 10199.20 & 50.73 \\
\hline & & TWK & 31.24 & 94.20 & 31.76 & 13314.55 & 32.27 & 13311.82 & $46.60^{*}$ \\
\hline & & JIQ & 19.11 & 90.06 & 21.10 & 12244.02 & 23.08 & 12222.33 & 51.59 \\
\hline & & COFS & $-1.08^{*}$ & $62.49^{*}$ & $10.83^{*}$ & $5740.43^{*}$ & 22.73 & $5080.94^{*}$ & 61.16 \\
\hline & & OFS & 7.54 & 75.30 & 15.16 & 8191.36 & 22.79 & 7837.68 & 57.13 \\
\hline
\end{tabular}

is based on only job information. All the other methods that utilize the shop information work effectively and hence, they show some level of robustness with respect to machine breakdowns.
In general, OBE is the best method when used with FCFS. For the MOD and SPT rules, there is no single flowtime estimation method which is the best for every condition. It appears that OFS and COFS now compete with OBE, 
Table 7

Machine breakdown results for FCFS al low utilization

\begin{tabular}{|c|c|c|c|c|c|c|c|c|c|}
\hline$\varepsilon$ & $d$ level & Methods & ML & STDL & MT & MSL & MAL & MSQL & MF \\
\hline \multicolumn{10}{|c|}{ Balanced shop } \\
\hline \multirow{10}{*}{$90 \%$} & $d=5 \mathrm{p}$ & OBE & 3.54 & $10.91^{*}$ & $5.60^{*}$ & $131.93^{*}$ & $7.66^{*}$ & $111.57^{*}$ & 30.65 \\
\hline & & TWK & 14.27 & 19.29 & 15.67 & 583.43 & 17.07 & 570.29 & 30.65 \\
\hline & & JIQ & 4.70 & 12.72 & 6.94 & 184.45 & 9.19 & 160.61 & 30.65 \\
\hline & & COFS & -4.97 & 25.67 & 6.01 & 691.05 & 16.99 & 148.20 & 30.65 \\
\hline & & OFS & $-0.49^{*}$ & 21.53 & 7.37 & 465.19 & 15.23 & 196.94 & 30.65 \\
\hline & $d=15 \mathrm{p}$ & OBE & 5.26 & $17.03^{*}$ & $8.18^{*}$ & $318.77^{*}$ & $11.11^{*}$ & 282.09* & 38.59 \\
\hline & & TWK & 22.22 & 26.73 & 23.50 & 1220.84 & 24.78 & 1208.91 & 38.59 \\
\hline & & JIQ & 6.89 & 18.76 & 9.81 & 401.12 & 12.72 & 361.52 & 38.59 \\
\hline & & COFS & -8.09 & 37.34 & 8.38 & 1475.19 & 24.85 & 324.62 & 38.59 \\
\hline & & OFS & $0.86^{*}$ & 29.64 & 10.97 & 881.74 & 21.09 & 450.33 & 38.59 \\
\hline \multirow[t]{10}{*}{$80 \%$} & $d=5 \mathrm{p}$ & OBE & 8.57 & $15.63^{*}$ & 10.46 & 318.92* & $12.35^{*}$ & 296.03 & 51.58 \\
\hline & & TWK & 35.21 & 32.34 & 35.69 & 2333.23 & 36.17 & 2329.63 & 51.58 \\
\hline & & JIQ & 11.22 & 18.49 & 13.26 & 470.98 & 15.10 & 445.62 & 51.58 \\
\hline & & COFS & -16.79 & 43.87 & $6.42^{*}$ & 2272.70 & 29.63 & $210.61^{*}$ & 51.58 \\
\hline & & OFS & $0.99^{*}$ & 29.55 & 11.28 & 880.62 & 21.57 & 444.25 & 51.58 \\
\hline & $d=15 \mathrm{p}$ & OBE & 11.92 & $25.15^{*}$ & 15.48 & 775.91* & $19.05^{*}$ & 711.75 & 66.82 \\
\hline & & TWK & 50.44 & 41.74 & 50.87 & 4354.75 & 51.30 & 4351.50 & 66.82 \\
\hline & & JIQ & 15.48 & 27.93 & 18.77 & 1023.57 & 22.05 & 961.45 & 66.82 \\
\hline & & COFS & -26.60 & 62.22 & $8.80^{*}$ & 4703.74 & 44.20 & 422.83* & 66.82 \\
\hline & & OFS & $4.54^{*}$ & 38.76 & 16.88 & 1530.01 & 29.21 & 914.80 & 66.82 \\
\hline \multicolumn{10}{|c|}{ Unbalanced shop } \\
\hline \multirow[t]{10}{*}{$90 \%$} & $d=5 \mathrm{p}$ & OBE & 4.02 & $11.42^{*}$ & $6.04^{*}$ & $147.17^{*}$ & $8.07^{*}$ & $126.38^{*}$ & 35.23 \\
\hline & & TWK & 17.31 & 23.76 & 18.94 & 889.30 & 20.57 & 871.44 & 35.23 \\
\hline & & JIQ & 4.84 & 13.86 & 7.40 & 217.13 & 9.95 & 185.96 & 35.23 \\
\hline & & COFS & -6.90 & 31.16 & 6.56 & 1045.77 & 20.01 & 183.65 & 35.23 \\
\hline & & OFS & $0.52^{*}$ & 24.39 & 8.90 & 599.79 & 17.28 & 291.32 & 35.23 \\
\hline & $d=15 \mathrm{p}$ & OBE & 5.73 & $17.78^{*}$ & 8.71 & $350.37^{*}$ & $11.69^{*}$ & $309.75^{*}$ & 43.89 \\
\hline & & TWK & 25.97 & 30.61 & 27.41 & 1644.93 & 28.86 & 1629.11 & 43.89 \\
\hline & & JIQ & 6.86 & 19.97 & 10.24 & 448.29 & 13.63 & 394.61 & 43.89 \\
\hline & & COFS & -11.29 & 43.90 & 8.68 & 2111.39 & 28.66 & 360.78 & 43.89 \\
\hline & & OFS & $2.38^{*}$ & 32.01 & 12.69 & 1034.72 & 23.00 & 580.33 & 43.89 \\
\hline \multirow[t]{10}{*}{$80 \%$} & $d=5 \mathrm{p}$ & OBE & 12.09 & $20.13^{*}$ & 14.39 & $570.59^{*}$ & $16.69^{*}$ & 533.18 & 87.82 \\
\hline & & TWK & 69.91 & 61.84 & 70.38 & 9954.84 & 70.85 & 9951.02 & 87.82 \\
\hline & & JIQ & 18.07 & 25.22 & 19.92 & 1028.52 & 21.77 & 1001.07 & 87.82 \\
\hline & & COFS & -61.66 & 107.78 & $6.58^{*}$ & 20493.23 & 74.82 & $381.29^{*}$ & 87.82 \\
\hline & & OFS & 13.77 & 52.73 & 27.10 & 3403.72 & 40.43 & 2611.44 & 87.82 \\
\hline & $d=15 \mathrm{p}$ & OBE & $15.25^{*}$ & $27.85^{*}$ & 18.87 & $1023.75^{*}$ & $22.49^{*}$ & 951.60 & 101.11 \\
\hline & & TWK & 83.20 & 67.47 & 83.64 & 13030.48 & 84.08 & 13026.86 & 101.11 \\
\hline & & JIQ & 21.35 & 32.62 & 24.53 & 1589.56 & 27.72 & 1523.02 & 101.11 \\
\hline & & COFS & -80.31 & 129.79 & $7.80^{*}$ & 33532.62 & 95.91 & 499.08* & 101.11 \\
\hline & & OFS & 18.94 & 57.02 & 32.23 & 4126.43 & 45.53 & 3322.97 & 101.11 \\
\hline
\end{tabular}

because they use the flowtime information of the most recently completed jobs. This information helps in capturing the changes of the shop conditions more effectively as compared to the other information used in the methods.

\subsection{Processing time variation}

In practice, processing times are estimated by some mechanisms (e.g., statistical methods, work-time study, etc.). 
Table 8

Machine breakdown results for SPT at low utilization

\begin{tabular}{|c|c|c|c|c|c|c|c|c|c|}
\hline$\varepsilon$ & $d$ level & Methods & ML & STDL & MT & MSL & MAL & MSQL & MF \\
\hline \multicolumn{10}{|c|}{ Balanced shop } \\
\hline \multirow{10}{*}{$90 \%$} & $d=5 \mathrm{p}$ & OBE & 5.38 & $13.91^{*}$ & 6.73 & $224.64^{*}$ & 8.08* & 216.83 & 20.14 \\
\hline & & TWK & 6.22 & 15.37 & 7.65 & 278.56 & 9.08 & 269.47 & 20.14 \\
\hline & & JIQ & 3.87 & 14.98 & 6.10 & 242.26 & 8.34 & 227.32 & 20.14 \\
\hline & & COFS & -2.19 & 22.93 & $5.67^{*}$ & 535.17 & 13.53 & 195.59* & 20.14 \\
\hline & & OFS & $-1.67^{*}$ & 22.58 & 5.83 & 517.17 & 13.33 & 201.99 & 20.14 \\
\hline & $d=15 \mathrm{p}$ & OBE & 8.65 & $20.78^{*}$ & 10.17 & $510.56 *$ & $11.69^{*}$ & 500.54 & 24.63 \\
\hline & & TWK & 10.71 & 23.07 & 12.15 & 653.28 & 13.59 & 644.00 & 24.63 \\
\hline & & JIQ & 6.80 & 22.24 & 9.59 & 545.41 & 12.38 & 521.48 & 24.63 \\
\hline & & COFS & -1.81 & 31.37 & $8.56^{*}$ & 993.88 & 18.93 & $431.48^{*}$ & 24.63 \\
\hline & & OFS & $-0.71^{*}$ & 30.60 & 8.90 & 942.64 & 18.51 & 451.49 & 24.63 \\
\hline \multirow[t]{10}{*}{$80 \%$} & $d=5 \mathrm{p}$ & OBE & 12.28 & $26.26^{*}$ & 13.24 & $866.20^{*}$ & 14.19 & 860.36 & 29.11 \\
\hline & & TWK & 15.19 & 28.89 & 15.83 & 1098.26 & 16.48 & 1095.01 & 29.11 \\
\hline & & JIQ & 10.05 & 28.36 & 12.07 & 935.47 & $14.09^{*}$ & 919.69 & 29.11 \\
\hline & & COFS & -2.86 & 35.26 & $8.44^{*}$ & 1278.11 & 19.74 & $643.24^{*}$ & 29.11 \\
\hline & & OFS & $-1.29^{*}$ & 34.53 & 8.92 & 1221.06 & 19.13 & 676.69 & 29.11 \\
\hline & $d=15 \mathrm{p}$ & OBE & 19.30 & $35.17^{*}$ & 20.57 & $1631.59^{*}$ & $21.84^{*}$ & 1621.18 & 38.79 \\
\hline & & TWK & 24.86 & 38.63 & 25.53 & 2139.07 & 26.19 & 2135.52 & 38.79 \\
\hline & & JIQ & 16.38 & 37.55 & 19.33 & 1703.06 & 22.28 & 1669.16 & 38.79 \\
\hline & & COFS & -2.98 & 45.85 & $12.90^{*}$ & 2132.43 & 28.78 & $1055.47^{*}$ & 38.79 \\
\hline & & OFS & 0.34* & 44.18 & 13.93 & 1971.26 & 27.52 & 1141.49 & 38.79 \\
\hline \multicolumn{10}{|c|}{ Unbalanced shop } \\
\hline \multirow[t]{10}{*}{$90 \%$} & $d=5 \mathrm{p}$ & OBE & 5.90 & $19.22^{*}$ & 7.42 & $425.17^{*}$ & 8.94* & $413.75^{*}$ & 21.47 \\
\hline & & TWK & 7.13 & 21.74 & 8.62 & 551.75 & 10.11 & 541.92 & 21.47 \\
\hline & & JIQ & 4.36 & 21.46 & 6.90 & 506.51 & 9.45 & 487.62 & 21.47 \\
\hline & & COFS & -0.29 & 27.04 & 6.91 & 756.26 & 14.11 & 430.26 & 21.47 \\
\hline & & OFS & $0.18^{*}$ & 26.86 & 7.07 & 745.86 & 13.96 & 440.11 & 21.47 \\
\hline & $d=15 \mathrm{p}$ & OBE & 9.23 & $24.93^{*}$ & 10.97 & 722.99* & $12.71^{*}$ & 707.66 & 26.29 \\
\hline & & TWK & 11.96 & 28.66 & 13.44 & 993.80 & 14.93 & 983.92 & 26.29 \\
\hline & & JIQ & 7.41 & 27.95 & 10.62 & 863.06 & 13.83 & 832.25 & 26.29 \\
\hline & & COFS & $0.75^{*}$ & 34.37 & $10.05^{*}$ & 1202.37 & 19.34 & 710.93 & 26.29 \\
\hline & & OFS & 1.75 & 33.94 & 10.40 & 1175.41 & 19.05 & 737.82 & 26.29 \\
\hline \multirow[t]{10}{*}{$80 \%$} & $d=5 \mathrm{p}$ & OBE & 18.21 & 93.54* & 19.42 & $13215.85^{*}$ & $20.62^{*}$ & $13205.82^{*}$ & 37.22 \\
\hline & & TWK & 22.88 & 100.32 & 23.51 & 14925.52 & 24.15 & 14922.21 & 37.22 \\
\hline & & JIQ & 14.74 & 100.03 & 18.19 & 14543.78 & 21.64 & 14501.94 & 37.22 \\
\hline & & COFS & $3.97^{*}$ & 102.11 & $15.92 *$ & 14613.95 & 27.87 & 13629.89 & 37.22 \\
\hline & & OFS & 6.09 & 101.95 & 16.65 & 14625.33 & 27.20 & 13782.86 & 37.22 \\
\hline & $d=15 \mathrm{p}$ & OBE & 24.69 & 93.40 & 26.34 & $13545.21^{*}$ & $27.99^{*}$ & 13525.72 & 46.77 \\
\hline & & TWK & 32.43 & 101.44 & 33.09 & 15845.06 & 33.76 & 15841.40 & 46.77 \\
\hline & & JIQ & 20.83 & 100.69 & 25.21 & 15059.67 & 29.60 & 14991.13 & 46.77 \\
\hline & & COFS & 4.99* & 103.01 & $20.33^{*}$ & 14939.49 & 35.68 & 13615.13 & 46.77 \\
\hline & & OFS & 8.72 & 102.49 & 21.66 & 14927.20 & 34.59 & 13890.89 & 46.77 \\
\hline
\end{tabular}

These estimates are then used to make various decisions such as due date assignment and scheduling. However, actual processing times realized on the machines can be quite different than the estimated quantities due to variations in machining conditions, material, etc. In order to model this situation, we perturb the processing times in the experiments. The initial estimates are still drawn from the exponential distribution but only some percentages (plus or minus) of the sampled 


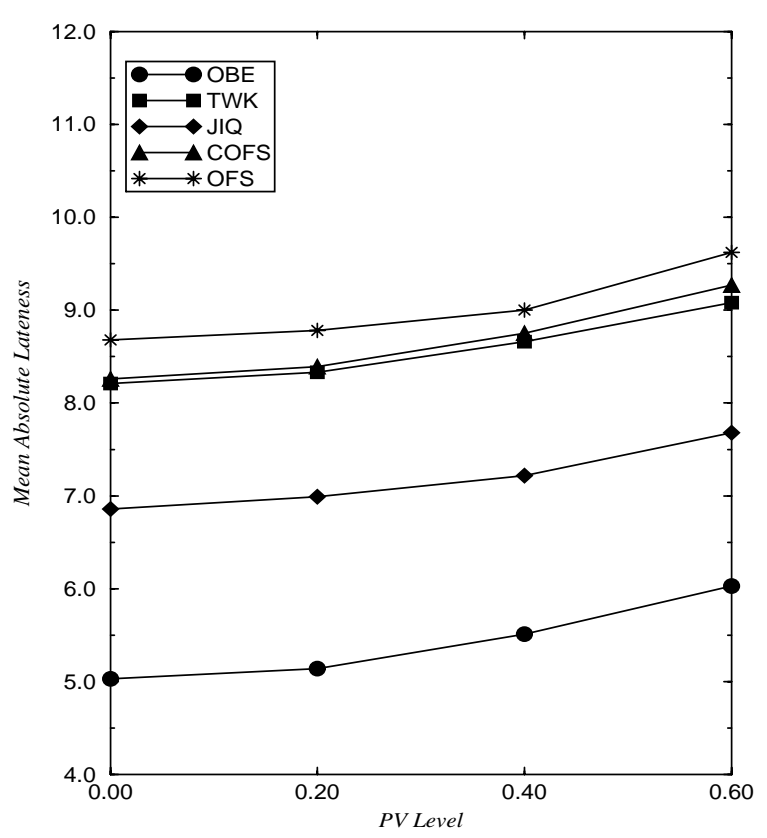

(a) Balanced

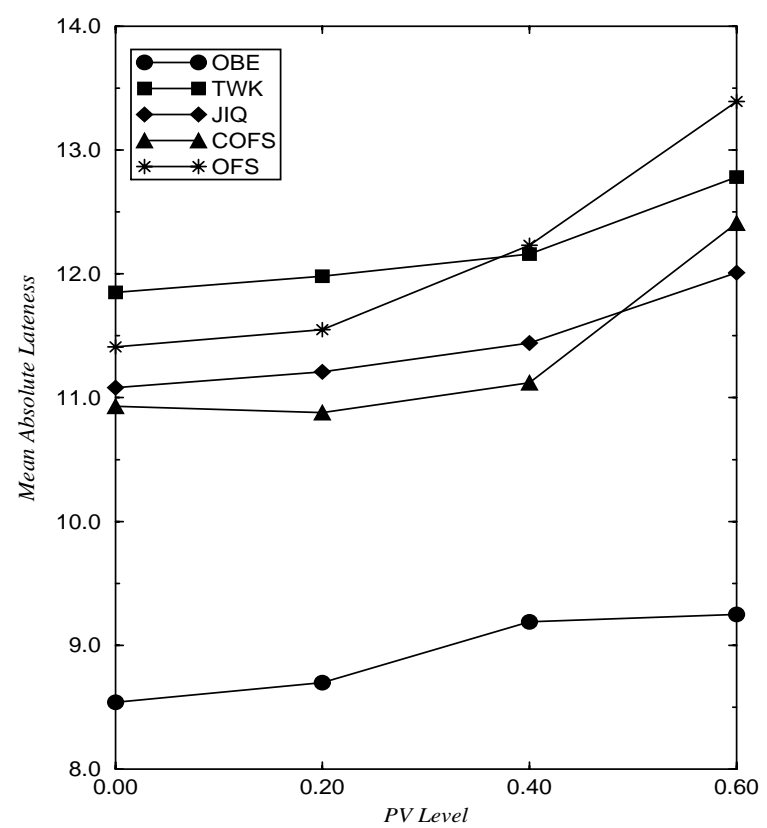

(b) Unbalanced

Fig. 1. Mean absolute lateness (MAL) versus processing time variation (PV).

quantities are used as the actual processing times in simulation runs. We use the following model for processing time variation:

$$
p_{i j}^{\prime}=(1+V \times U[-1,+1]) \times p_{i j},
$$

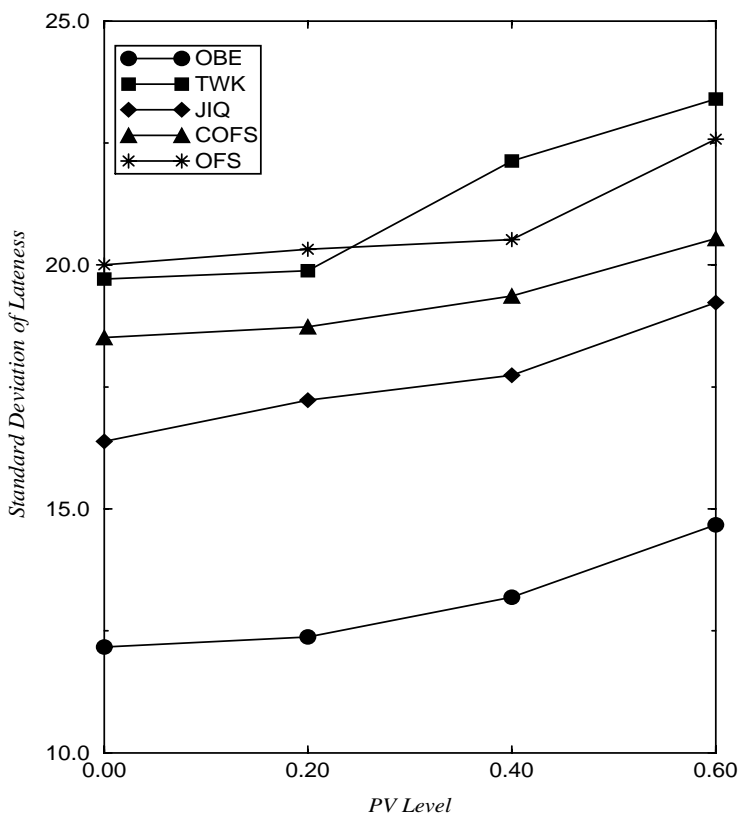

(a) Balanced

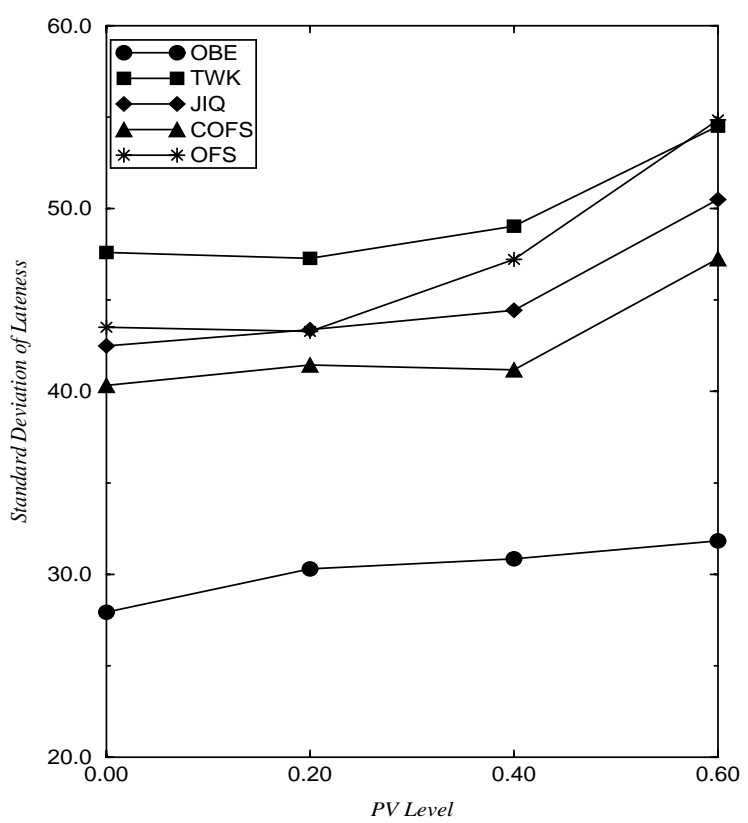

(b) Unbalanced

Fig. 2. Standard deviation of lateness (STDL) versus processing time variation $(\mathrm{PV})$.

where $p_{i j}$ is the processing time value drawn from the exponential distribution function (estimate of the processing time), $V$ is the level of the processing time variation, $U[-1,+1]$ is the uniform distribution with a minimum value -1 and a maximum value $+1, p_{i j}^{\prime}$ is the processing time deviated from its estimated value (actual value of processing time). 
Table 9

Load variation results for MOD at low utilization (65\%)

\begin{tabular}{|c|c|c|c|c|c|c|c|c|}
\hline $\begin{array}{l}\text { LV } \\
\text { level }\end{array}$ & $\begin{array}{l}\text { Flowtime } \\
\text { estimation }\end{array}$ & ML & STDL & MT & MSL & MAL & MSQL & MF \\
\hline \multicolumn{9}{|c|}{ Balanced shop } \\
\hline \multirow[t]{5}{*}{$\mathrm{LV}=10 \%$} & OBE & 0.62 & $6.04^{*}$ & 2.15 & $37.49^{*}$ & $3.68^{*}$ & $30.34^{*}$ & 14.76 \\
\hline & TWK & 0.67 & 8.10 & 2.76 & 67.56 & 4.85 & 53.12 & $14.54^{*}$ \\
\hline & JIQ & $-0.05^{*}$ & 6.66 & $1.95^{*}$ & 45.08 & 3.96 & 34.76 & 14.88 \\
\hline & COFS & -0.97 & 11.66 & 2.94 & 137.50 & 6.86 & 41.69 & 15.28 \\
\hline & OFS & -1.17 & 11.96 & 2.90 & 145.23 & 6.98 & 41.74 & 15.27 \\
\hline \multirow[t]{5}{*}{$\mathrm{LV}=20 \%$} & OBE & 0.55 & $5.96^{*}$ & 2.10 & $36.46^{*}$ & $3.65^{*}$ & $29.28^{*}$ & 14.58 \\
\hline & TWK & 0.49 & 8.19 & 2.70 & 69.57 & 4.90 & 53.94 & $14.35^{*}$ \\
\hline & JIQ & $-0.12^{*}$ & 6.64 & $1.91^{*}$ & 45.09 & 3.94 & 34.61 & 14.70 \\
\hline & COFS & -0.89 & 11.48 & 2.95 & 133.21 & 6.79 & 40.68 & 15.11 \\
\hline & OFS & -1.11 & 11.86 & 2.92 & 142.58 & 6.95 & 41.63 & 15.09 \\
\hline \multicolumn{9}{|c|}{ Unbalanced shop } \\
\hline \multirow[t]{5}{*}{$\mathrm{LV}=10 \%$} & OBE & 0.82 & $7.40^{*}$ & 2.42 & $57.11^{*}$ & $4.01^{*}$ & $48.17^{*}$ & 15.55 \\
\hline & TWK & $-0.07^{*}$ & 10.16 & 2.65 & 107.55 & 5.37 & 84.69 & $15.30 *$ \\
\hline & JIQ & -0.29 & 8.79 & $2.07^{*}$ & 80.85 & 4.42 & 67.15 & 15.69 \\
\hline & COFS & -1.35 & 13.24 & 3.00 & 178.40 & 7.35 & 54.42 & 16.21 \\
\hline & OFS & -1.11 & 13.07 & 3.10 & 173.45 & 7.31 & 62.97 & 16.13 \\
\hline \multirow[t]{5}{*}{$\mathrm{LV}=20 \%$} & OBE & 0.75 & $7.73^{*}$ & 2.39 & $63.23^{*}$ & $4.03^{*}$ & 53.92* & 15.43 \\
\hline & TWK & -0.19 & 10.76 & 2.68 & 123.55 & 5.55 & 98.70 & $15.17^{*}$ \\
\hline & JIQ & -0.37 & 9.16 & $2.05^{*}$ & 89.56 & 4.47 & 75.34 & 15.53 \\
\hline & COFS & -1.26 & 13.52 & 3.05 & 186.23 & 7.36 & 58.61 & 16.03 \\
\hline & OFS & -1.08 & 13.54 & 3.14 & 187.14 & 7.36 & 69.83 & 15.98 \\
\hline
\end{tabular}

The flowtime methods are tested under three levels of processing time variation, $V=0.2,0.4$ and 0.6 for both the balanced and unbalanced shop conditions.

As displayed in Figs. 1 and 2, the performance of the flowtime estimation methods deteriorate as the processing time variation level $(V)$ increases. In general, OBE is the best rule. It is also robust with respect to processing time variations. The processing time variation affects the performance of the methods at the same rate except for the TWK and OFS methods. When the system is unbalanced, OFS reacts more to the changes in processing time variation for both MAL and STDL. The same behavior is observed for TWK in the balanced shop for the MAL performance.

\subsection{Load variation}

In our study, we also consider load variations to model possible changes in the demand rates due to external factors. In the model, load variation is adjusted by varying the arrival rate of the jobs to the system. This means that the load level of system (consequently, the utilization of the machines) changes over time. Based on pilot experiments, we change the system load level after the completion of every 500 jobs. The arrival rate is updated to a new value as follows:

$a^{\prime}=U\left[a_{\mathrm{LV}}^{\mathrm{H}}, a_{\mathrm{LV}}^{\mathrm{L}}\right]$, where LV is the load variation level, $a^{\prime}$ the updated arrival rate, $a_{\mathrm{LV}}^{\mathrm{H}}$ the arrival rate which makes the load level of the system LV percent higher than the average load level of the system and $a_{\mathrm{LV}}^{\mathrm{L}}$ is the arrival rate which makes the load level of the system LV percent lower than the average load level of the system.

Again two levels of load variation is used in the experiments $(\mathrm{LV}=10 \%$ and $20 \%)$.

The results are given in Table 9. In contrast to the previous two cases, the flowtime estimation methods are not considerably affected by the load variation. This means that the system compensates itself in the long-run for the arrival rate variations. We also note that the system recovers from the load variation easily at low utilization. It is also observed that OBE performs better than the other estimation methods for all dispatching rules except for the ML and MT performance measures.

\section{Discussion}

In this study, we developed a new method for estimating the job flowtimes in a dynamic job shop environment. The proposed method uses the detailed job, shop and route information for each operation of a job and produces 
flowtime estimates on the operational basis. The method considers explicitly the machine imbalance information in the estimation process.

To test the performance of the flowtime estimation methods, we conducted a full factorial design with four factors (flowtime estimation method, dispatching rule, shop utilization and shop balance). The proposed method was compared with two popular methods (JIQ and TWK) and two recently proposed methods (COFS and OFS). A wide variety of performance measures were used to compare the estimation methods.

First stage experiments with regression analyses indicated that the estimated equations for FCFS explain a larger proportion of variation of the flowtimes when compared to MOD and SPT rules. This is due to the fact that SPT and MOD create a more dynamic environment which makes it difficult to estimate the job flowtimes.

Second stage analysis showed that as the shop balance deteriorates and/or the utilization level increases, the performance of the estimation methods also deteriorate. The results also indicated that the proposed method (OBE) performed better than other methods with some exceptions with respect to the mean lateness and mean tardiness measures. Duncan's Multiple Range test also reinforced the fact that OBE is the overall best.

At the final stage, we measured the sensitivity of the flowtime estimation methods to variability in the shop conditions. The results showed that the flowtime estimation methods are quite sensitive to machine breakdowns and processing time variation but not so much to load variations.

The results presented in this paper also provide useful information for practitioners. First, as shown in this paper, the performance of the manufacturing systems can considerably be improved by using the information intensive methods rather than the simple methods (i.e., TWK). Second, the use of detailed information in estimating flowtimes provides significant improvement in the system performance over the other methods that utilize more aggregate information. In today's computer based environments, it is relatively easy now to collect and process the detailed information. Hence, the shop managers can implement more sophisticated and information intensive methods such as OBE.

Third, the results of this study indicated that estimating flowtimes for each operation (i.e., operation by operation) is a better approach than the traditional job based estimation. Note that similar conclusions were drawn in the scheduling literature in which operation-based due date rules were found better than the job-based rules. And fourth, managers should pay attention to the reliability of machines and variability in operation times in the flowtime estimation. Because our results indicated that variability in the system can affect the system performance more than the load level. The practical implication of this finding is that variability and uncertainty are two real enemies of modern production systems and reducing their levels may worth more than benefits of using more sophisticated shop floor planning and control systems.
As to the implementation issues, the parameters of the proposed approach can be determined either using the real data or simulated data. Of course, the latter approach is easier to implement since a valid simulation model of the system can quickly produce the necessary data for the analysis. In the former case, however, the data is collected either automatically by sensors and computer systems or by the help of human operator. With today's computing power and easy-to-use statistical packages in computer-integrated manufacturing systems, the analysis can also quickly be done in the off-line mode. Besides, one does not have to change the parameters frequently. The analysis can be done whenever there is a need for that (i.e., when there is major changes production practice). Even if the system conditions change during the daily operations of the system, the regression coefficient can be obtained from the table look-up functions which could be established in advance for each experimental condition. In short, the computational burden of the proposed method is not high. Besides, the other flowtime estimation methods (e.g., TWK) also require one or more parameters to be estimated in the same fashion.

As a further research topic, the proposed flowtime estimation method can be combined with a due date setting procedure to attain some other system performance objectives (i.e., minimization of costs or meeting some service level constraints, etc.). Secondly, operational flow time estimates generated by the proposed method can be used in several shop floor decisions such as scheduling, rerouting of jobs, order review/release, expedition of jobs, or any other area which makes use of flowtime information. Thirdly, in the analysis of simulation results we note that $R^{2}$ values of regression coefficients are relatively higher for the first few operations of the jobs. Thus, we expect that the same good performance from OBE in large systems as the flowtime estimates of the earlier operations in the sequence can dominate the entire estimation process. Since it also employs more detailed information about the shop status, we expect OBE to perform better than the other methods in larger systems (i.e., a system with more than 5 machines). But this conjecture remains to be tested in future studies. Finally, the methodology proposed in this study can be extended to the environments in which the effects machine breakdowns, processing time variations and load variations are explicitly considered during model constructions.

\section{References}

[1] Blackstone JH, Phillips DT, Hogg GL. A state-of-the art survey of dispatching rules for manufacturing job shop operations. International Journal of Production Research 1982;20(1):27-45.

[2] Ramasesh R. Dynamic job shop scheduling: a survey of simulation research. OMEGA-International Journal of Management Sciences 1990;18(1):43-57. 
[3] Ragatz GL, Mabert VA. A simulation analysis of due date assignment rules. Journal of Operations Management 1984;5(1):27-39.

[4] Eilon S, Chowdhury IG. Due dates in job shop scheduling. International Journal of Production Research 1976;14(2): 223-37.

[5] Bertrand JWM. The effect of workload dependent due dates on job shop performance. Management Science 1983;29(7): 799-816.

[6] Vig MM, Dooley KJ. Dynamic rules for due date assignment. International Journal of Production Research 1991;29(7): 1361-77.

[7] Vig MM, Dooley KJ. Mixing static and dynamic estimates for due date assignment. Journal of Operations Management 1993;11:67-79.

[8] Gee ES, Smith CH. Selecting allowance policies for improved job shop performance. International Journal of Production Research 1993;31(8):1839-52.

[9] Cheng TCE. Simulation study of job shop scheduling with due dates. International Journal of Systems Science 1988;19(3):383-90.

[10] Cheng TCE, Gupta MC. Survey of scheduling research involving due date determination decisions. European Journal of Operational Research 1989;38:156-66.

[11] Conway RW. Priority dispatching and job lateness in a jop shop. Journal of Industrial Engineering 1965;16:228-37.

[12] Eilon S, Hodgson RM. Job shop scheduling with due dates. International Journal of Production Research 1967;6(1):1-13.

[13] Enns ST. Job shop flowtime prediction and tardiness control using queueing analysis. International Journal of Production Research 1993;31:2045-57.

[14] Miyazaki S. Combined scheduling system for reducing job tardiness in a job shop. International Journal of Production Research 1981;19(2):201-11.

[15] Taylor BW, Moore LJ. Estimating job flowtimes in a job shop for contractually negotiated due dates. Journal of Operational Research Society 1982;33:845-54.

[16] Enns ST. Job shop leadtime requirements under conditions of controlled delivery performance. European Journal of Operational Research 1994;77:429-39.

[17] Enns ST. A dynamic forecasting model for job shop flowtime prediction and tardiness control. International Journal of Production Research 1995;33(5):1295-312.

[18] Cheng TCE. Due date determination for a single machine shop with SPT dispatching. Engineering Costs and Production Economics 1986;10:35-41.
[19] Cheng TCE. Optimal due date assignment in an assembly shop. International Journal of Operations and Production Management 1994;14(2):31-42.

[20] Shanthikumar JG, Buzacott JA. Open queueing network models of dynamic job shops. International Journal of Production Research 1981;19:255-66.

[21] Buzacott JA, Shanthikumar JG. On approximate queueing models of dynamic job shops. Management Science 1985;31:870-87.

[22] Shanthikumar JG, Sumita U. Approximations for the time spent in a dynamic job shop with applications to due date assignment. International Journal of Production Research 1988;26(8):1329-52.

[23] Lawrence SR. Estimating flowtimes and setting due dates in complex production systems. IIE Transactions 1995;27: 657-68.

[24] Enns ST. Lead time selection and the behavior of work flow in job shops. European Journal of Operational Research 1998;109:122-36.

[25] Weeks JK. A simulation study of predictable due dates. Management Science 1979;25(4):363-73.

[26] Kanet JJ, Christy DP. Manufacturing systems with forbidden early shipment: implications for setting manufacturing lead times. International Journal of Production Research 1989;27(5):783-92.

[27] Fry TD, Philipoom PR, Markland RE. Due date assignment in a multistage job shop. IIE Transactions 1989;21(2):153-61.

[28] Kaplan AC, Unal AT. A probabilistic cost-based due date assignment model for job shops. International Journal of Production Research 1993;31(12):2817-34.

[29] Philipoom PR, Rees LP, Wiegmann L. Using neural networks to determine internally-set due date assignments for job shop scheduling. Decision Sciences 1994;25(5/6):825-51.

[30] Cheng TCE. Analysis of job flowtime in a job shop. Journal of Operational Research Society 1985;36(3):225-30.

[31] Pegden CD, Shannon RE, Sadowski RP. Introduction to simulation using SIMAN. New Jersey: McGraw-Hill, 1990.

[32] Weisberg S. Applied linear regression. New York: Wiley, 1985.

[33] Neter J, Wasserman W, Kutner MH. Applied linear statistical models. Boston: IRWIN, 1990.

[34] Schultz CR. An expediting heuristic for the shortest processing time dispatching rule. International Journal of Production Research 1989;27(1):31-41.

[35] Law AM, Kelton WD. Simulation modeling and analysis. New York: McGraw-Hill, 1991. 